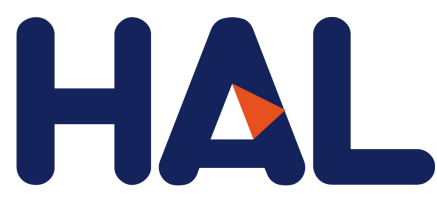

archives-ouvertes

\title{
A proteomic study of resistance to Brown Ring disease in the Manila clam, Ruditapes philippinarum
}

M. Smits, Sébastien Artigaud, B. Bernay, Vianney Pichereau, L. Bargelloni, Christine Paillard

\section{To cite this version:}

M. Smits, Sébastien Artigaud, B. Bernay, Vianney Pichereau, L. Bargelloni, et al.. A proteomic study of resistance to Brown Ring disease in the Manila clam, Ruditapes philippinarum. Fish and Shellfish Immunology, Elsevier, 2020, 99, pp.641-653. 10.1016/j.fsi.2020.02.002 hal-03094103

\section{HAL Id: hal-03094103 \\ https://hal.archives-ouvertes.fr/hal-03094103}

Submitted on 4 Jan 2021

HAL is a multi-disciplinary open access archive for the deposit and dissemination of scientific research documents, whether they are published or not. The documents may come from teaching and research institutions in France or abroad, or from public or private research centers.
L'archive ouverte pluridisciplinaire $\mathbf{H A L}$, est destinée au dépôt et à la diffusion de documents scientifiques de niveau recherche, publiés ou non, émanant des établissements d'enseignement et de recherche français ou étrangers, des laboratoires publics ou privés. 


\section{Journal Pre-proof}

A proteomic study of resistance to Brown Ring disease in the Manila clam, Ruditapes philippinarum

M. Smits, S. Artigaud, B. Bernay, V. Pichereau, L. Bargelloni, C. Paillard

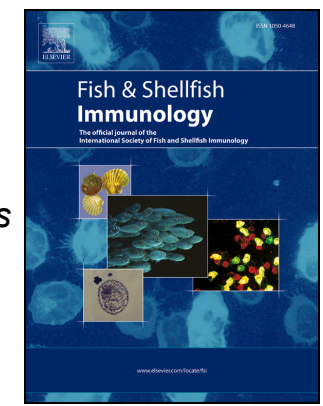

PII:

S1050-4648(20)30073-5

DOI:

https://doi.org/10.1016/j.fsi.2020.02.002

Reference: $\quad$ YFSIM 6801

To appear in: Fish and Shellfish Immunology

Received Date: 28 October 2019

Revised Date: 24 January 2020

Accepted Date: 1 February 2020

Please cite this article as: Smits M, Artigaud S, Bernay B, Pichereau V, Bargelloni L, Paillard C, A proteomic study of resistance to Brown Ring disease in the Manila clam, Ruditapes philippinarum, Fish and Shellfish Immunology (2020), doi: https://doi.org/10.1016/j.fsi.2020.02.002.

This is a PDF file of an article that has undergone enhancements after acceptance, such as the addition of a cover page and metadata, and formatting for readability, but it is not yet the definitive version of record. This version will undergo additional copyediting, typesetting and review before it is published in its final form, but we are providing this version to give early visibility of the article. Please note that, during the production process, errors may be discovered which could affect the content, and all legal disclaimers that apply to the journal pertain.

(C) 2020 Published by Elsevier Ltd. 


\section{Credit Author Statement}

Morgan Smits : Conceptualization, Methodology, Formal analysis, Writing - original draft

Sébastien Artigaud : Formal analysis, Data curation, Validation, Writing - original draft

Benoit Bernay : Resources, Software, Formal analysis

Vianney Pichereau : Data curation, Validation, Supervision, Writing - review \& editing

Luca Bargelloni : Supervision, Funding acquisition, Resources

Christine Paillard : Supervision, Funding acquisition, Project administration, Writing - review \& editing 
A PROTEOMIC STUDY OF RESISTANCE TO BROWN RING DISEASE IN THE MANILA

CLAM, Ruditapes philippinarum.

M. Smits ${ }^{1,2}$, S. Artigaud ${ }^{1}$, B, Bernay ${ }^{3}$, V. Pichereau ${ }^{1}$, L. Bargelloni ${ }^{2}$, C. Paillard $^{1}$

${ }^{1}$ Université de Brest, CNRS, IRD, Ifremer, UMR 6539 LEMAR, F-29280 Plouzané - France.

${ }^{2}$ Department of Comparative Biomedicine and Food Science, University of Padova, Agripolis Campus, Viale dell'Universita', 16, 35020 Legnaro (PD) - Italy.

${ }^{3}$ Plateforme Proteogen, SFR ICORE 4206, Université de Caen Basse-Normandie, Esplanade de la paix, 14032 Caen cedex - France.

\section{ABSTRACT}

12 Marine mollusk aquaculture has more than doubled over the past twenty years, accounting for over $1315 \%$ of total aquaculture production in 2016. Infectious disease is one of the main limiting factors to 14 the development of mollusk aquaculture, and the difficulties inherent to combating pathogens through antibiotic therapies or disinfection have led to extensive research on host defense mechanisms and hostpathogen relationships. It has become increasingly clear that characterizing the functional profiles of response to a disease is an essential step in understanding resistance mechanisms and moving towards more effective disease control. The Manila clam, Ruditapes philippinarum, is a main cultured bivalve species of economic subject to Brown Ring Disease (BRD), an infection induced by the bacterium Vibrio tapetis.

21 In this study, juvenile Manila clams were subjected to a 28-day controlled challenge with Vibrio 22 tapetis, and visual and molecular diagnoses were carried out to distinguish two extreme phenotypes 23 within the experimental clams: uninfected ("RES", resistant) and infected ("DIS", diseased) post24 challenge. Total protein extractions were carried out for resistant and diseased clams, and proteins were 25 identified using LC-MS/MS. Protein sequences were matched against a reference transcriptome of the 26 Manila clam, and protein intensities based on label-free quantification were compared to reveal 49 27 significantly accumulated proteins in resistant and diseased clams. Proteins with known roles in 28 pathogen recognition, lysosome trafficking, and various aspects of the energy metabolism were more 29 abundant in diseased clams, whereas those with roles in redox homeostasis and protein recycling were more abundant in resistant clams.

31 Overall, the comparison of the proteomic profiles of resistant and diseased clams after a month-long 32 controlled challenge to induce the onset of Brown Ring disease suggests that redox homeostasis and 33 maintenance of protein structure by chaperone proteins may play important and interrelated roles in 34 resistance to infection by Vibrio tapetis in the Manila clam. 


\section{INTRODUCTION}

36 Mollusks represent over a fifth of the global aquaculture market, accounting for USD 29.2 billion in 2016 of which the most heavily traded species are oysters, clams, scallops, and mussels.

38 Originating from the Asian Pacific coast, the Manila clam, Ruditapes philippinarum has become the second major cultured bivalve in the world, with over 4.4 million tons per year produced worldwide [1]. This species was introduced to the French Atlantic coast for aquaculture diversification in the 1970s [2], and following a rapid increase in clam production, mortality events became increasingly frequent and severe, eventually leading to the closure of many clam production parks [3]. The mass mortality episodes were subsequently associated to Brown Ring disease (BRD) [4,5], a chronic extra-pallial infection caused by Vibrio tapetis. After initial proliferation of the bacteria in the extra-pallial compartment, diseased clams manifest abnormal conchiolin deposits along the inner surface of the shell. In severe infections, the pathogen may cause lesions in the mantle and penetrate the hemolymph, in which case septicemia and death occur within 4-5 days [6,7].

49 In France, BRD continues to negatively impact production and prevalence can reach $80-100 \%$

50 [8] along the Northern Atlantic coast. While the severity of the disease and the virulence of its 51 etiological agent are known to be largely dependent on a number of environmental factors, namely temperature and salinity, bivalves have a number of sophisticated stress and immune response mechanisms, as well as a highly specific innate immune system on which they rely to directly combat infection $[9,10]$. As marine bivalves lack an adaptive immune system, the innate genomic component of their immune system plays an essential role in mitigating the host response to pathogens.

Invertebrate innate immunity relies on a number of pathogen recognition factors that trigger signaling pathways involved in hemocyte recruitment, phagocytosis, and the production of a wide range of antimicrobial compounds for host defense. While resistance to infection in bivalves initially depends on the ability of mucosal interfaces to impede pathogen entrance into the host,

62 circulating hemocytes from fluids (such as hemolymph and extra-pallial fluids) and bioactive 63 molecules in the plasma are responsible for mediating the secondary host response through 64 phagocytosis and direct bacterial neutralization by antimicrobial effectors [11,12]. Interestingly, 65 clams have been shown to recover from BRD through shell repair processes, leading to the 
66 investigation of this resistant phenotype in several populations [13]. Previous gene expression

67 and transcriptomic studies on the Manila clam have led to the assembly of a transcriptome and 68 have shed light on several factors such as pathogen recognition and killing, modulation of 69 hemocyte cytoskeleton, regulation of apoptosis, and bio-mineralization that are likely to play key 70 roles in the innate immune response against bacterial infections [4-8,14-19]. The factors 71 influencing virulence and highlighting the dynamics of the infection process leading to Brown 72 Ring disease in the Manila clam are increasingly well described [8,20-23], and it is has become 73 clear that the interactions between host and pathogen during infection leads to a complex 74 remodeling of the molecular framework of both organisms, highlighting the importance of 75 understanding the changes in gene expression as well as those occurring on the proteomic level. 76 In addition, several studies focusing on Vibrio-induced expression of immune-related genes in $R$. 77 philippinarum suggest a tendency towards a downregulation of the inflammatory response and an 78 upregulation of genes related to homeostasis in this species, insisting on the importance of 79 investigating the molecular mechanisms at play to identify markers of resistance $[24,25]$. The 80 growing number of genomic and transcriptomic resources available for this host species have 81 unveiled particularly high levels of polymorphism, a factor that may mitigate the observed 82 functional variability in the immune response to pathogens [26,27], though to date there remains 83 a significant knowledge gap surrounding the functional response of the Manila clam to infection 84 with Vibrio tapetis, particularly in disease-resistant clams.

85 The present study aims to characterize the proteomic profiles of resistant and susceptible Manila 86 clams following infection with Vibrio tapetis. By comparing the functional response in these two 87 extreme phenotypes, we seek to shed light on the factors responsible for resistance to pathogens 88 in this invertebrate species. 


\section{MATERIALS AND METHODS}

\subsection{Experimental design and sampling}

Juvenile $R$. philippinarum (average shell length $12.37 \mathrm{~mm}$ ) from a cohort of mixed families produced at the SATMAR hatchery (Marennes, France) were acclimated for 12 days in aerated seawater tanks at $14^{\circ} \mathrm{C}$. An experimental group $(\mathrm{n}=1200)$ was exposed to air for 8 hours at $14^{\circ} \mathrm{C}$ to facilitate valve opening, then placed in a shallow tank and injected into the pallial cavity (without damaging the mantle epithelium) with $50 \mu \mathrm{L}$ of $V$. tapetis suspension (strain $\mathrm{CECT}_{4600^{\mathrm{T}}}$ ) prepared in filter-sterilized sea water (FSSW) containing $8.2 \times 10^{6}$ bacteria.mL $^{-1}$ (4.1 $\times 10^{5}$ bacteria injected per clam). A first control group $(\mathrm{C} 1 ; n=300)$ was injected with $50 \mu \mathrm{L}$ of FSSW, and a second control group $(\mathrm{C} 2 ; n=300)$ received no treatment. All clams (injected as well as not injected) were then kept in dry conditions for at least 6 hours to ensure that the injected clams retained the fluid, then returned to separate tanks in a thermoregulated room at $14^{\circ} \mathrm{C}$ with no food and constant aeration for four weeks, according to a standardized protocol established by Paillard \& Maes [28]. As BRD is a chronic infection localized in the extra-pallial compartment, injection into the pallial cavity mimics the natural infection process, whereas injecting tissues results in rapid septicemia for $V$. tapetis injections, or tissue disruption in the case of sterile filtered sea water injection into the tissues. Dead clams, when they occurred, were recorded daily and removed from the tanks. The seawater remained unchanged throughout the duration of the experiment. After the four-week incubation period, all clams were sampled for whole weight, shell weight, shell length, and each clam was individually opened with a cleaned scalpel over a tube, allowing whole tissues and fluids to be collected together, after which the sample was flash frozen in liquid nitrogen and stored at $-80^{\circ} \mathrm{C}$.

\subsection{Diagnostic methods}

For visual diagnosis, shells were observed under a binocular magnifier to identify and quantify the extent index of Brown Ring disease according to the classification system described by Paillard \& Maes (1994). For molecular diagnosis, DNA from whole-body tissue and fluid samples was analyzed. Briefly, the samples were homogenized in a volume of phosphate buffer saline (PBS; $\mathrm{pH}=7$ ) based on tissue weight, for a final concentration of $0.25 \mathrm{mg} / \mu \mathrm{L}$ tissue in the buffer. Ceramic beads were added to each sample and mechanical tissue disruption was done using 2 cycles of 20 seconds beating (10 sec. pause) at room temperature at $6.5 \mathrm{~m} / \mathrm{sec}$ on a 
121 FastPrep-24 benchtop homogenizer (MP-Bio). Total DNA extractions were carried out using 80

$122 \mu \mathrm{L}$ (eq. $20 \mathrm{mg}$ ) of the homogenate and the Nucleospin 96 Tissue Kit (Macherey-Nagel)

123 according to the manufacturer's protocol with minor adaptations (see detailed protocol in 124 supplementary file 1 ). The remaining homogenate was flash frozen and stored at $-80^{\circ} \mathrm{C}$ for 125 subsequent protein extractions. PCR mix was prepared with $1 \mu \mathrm{L}$ template DNA, $5 \mu \mathrm{L}$ GoTaq G2 126 Flexi buffer, $0.15 \mu \mathrm{L}$ GoTaq polymerase enzyme (1 U/ $\mu \mathrm{L}$ ), $0.5 \mu \mathrm{L}$ dNTP mix (each $10 \mathrm{mM}$ ), $127 \quad 17.35 \mu \mathrm{L} \mathrm{H}_{2} 0$, and $0.5 \mu \mathrm{L}$ of forward and reverse primers specific to the virB4 gene of the $V$. 128 tapetis strain $\mathrm{CECT}_{4600}{ }^{\mathrm{T}}$ (final volume $25 \mu \mathrm{L}$, adapted from Bidault et al. [28]). Initial 129 denaturation was done at $94^{\circ} \mathrm{C}$ for $5 \mathrm{~min}$, followed by 40 cycles of denaturation $\left(94^{\circ} \mathrm{C}\right)$, annealing $130\left(54^{\circ} \mathrm{C}\right)$, and extension $\left(72^{\circ} \mathrm{C}\right)$ for 30 seconds each, and a final extension step at $72^{\circ} \mathrm{C}$ for $3 \mathrm{~min}$. 131 PCR products were deposited on $1 \%$ agarose gel and electrophoresis was carried out at $110 \mathrm{~V}$ for $13245 \mathrm{~min}$. In total DNA samples containing V. tapetis DNA, a $173 \mathrm{bp}$ amplicon was then visible by 133 fluorescence.

\subsection{Total protein extraction and digestion}

136 Based on both visual and molecular diagnoses, samples were assigned to one of four categories 137 representative of the disease kinetics: BRD-/PCR- (0); BRD-/PCR+ (1); BRD+/PCR- (2); 138 BRD+/PCR+ (3). Total proteins were extracted from three samples from category 0 and three 139 samples from category 3 (presenting the same extent index of conchiolin deposit according to 140 Paillard \& Maes [29]), representing the extreme phenotypes hereafter referred to as "RES" 141 (Category 0) and "DIS" (Category 3). Sample homogenates were defrosted on ice and $10 \mu \mathrm{L}$ 142 protease inhibitor mix (GE Healthcare) was added. After mixing by vortex, the samples were 143 centrifuged at $15000 \mathrm{x}$ g for $10 \mathrm{~min}$ at $4^{\circ} \mathrm{C}$. The supernatant was transferred to a clean tube and 144 proteins were quantified according to the Bradford method [30]. Based on protein concentration, 145 the volume necessary for $50 \mu \mathrm{g}$ of total proteins was transferred to a clean tube and volume was 146 adjusted to $50 \mu \mathrm{L}$ with an ammonium bicarbonate (AmBic) solution (100 mM). Samples were 147 reduced with $5 \mu \mathrm{L}$ dithiothreitol $(10 \mathrm{mM})$ for 40 minutes at $56^{\circ} \mathrm{C}$, then alkylated with $10 \mu \mathrm{L}$ 148 iodoacetamide $(20 \mathrm{mM})$ for $30 \mathrm{~min}$ in the dark. Protein digestion was carried out at $37^{\circ} \mathrm{C}$ 149 overnight with $10 \mu \mathrm{L}$ trypsin buffer $(0.1 \mu \mathrm{g} / \mu \mathrm{L})$. After digestion, $5 \%$ formic acid was added and 150 peptide samples were dehydrated using a SpeedVac ${ }^{\mathrm{TM}}$ concentrator. 
154 Peptide quantification and identification was carried out through nano-LC MS/MS to allow for the comparison of the proteomic profiles of resistance to Brown Ring disease in the Manila clam.

156

\subsubsection{Sample Preparation for Mass Spectrometry Analysis}

For nano-LC fragmentation, peptide samples were first desalted and concentrated onto a $\mu \mathrm{C} 18$ Omix (Agilent) before analysis. The chromatography step was performed on a NanoElute (Bruker Daltonics) ultra-high pressure nano flow chromatography system. Peptides were concentrated onto a C18 pepmap $100(5 \mathrm{~mm}$ x $300 \mu \mathrm{m}$ i.d.) precolumn (Thermo Scientific) and separated at $50^{\circ} \mathrm{C}$ onto a Aurora reversed phase Reprosil column ( $25 \mathrm{~cm}$ x $75 \mu \mathrm{m}$ i.d.) packed with $1.6 \mu \mathrm{m} \mathrm{C18}$ coated porous silica beads (Ionopticks). Mobile phases consisted of $0.1 \%$ formic acid, $99.9 \%$ water (v/v) (A) and $0.1 \%$ formic acid in $99.9 \% \mathrm{ACN}(\mathrm{v} / \mathrm{v})(\mathrm{B})$. The nanoflow rate was set at $400 \mathrm{nl} / \mathrm{min}$, and the gradient profile was as follows: from 2 to $15 \% \mathrm{~B}$ within 60 min, followed by an increase to $25 \% \mathrm{~B}$ within $30 \mathrm{~min}$ and further to $37 \%$ within $10 \mathrm{~min}$, followed by a washing step at $95 \% \mathrm{~B}$ and reequilibration.

\subsubsection{Mass Spectrometry Analysis}

MS experiments were carried out on a TIMS-TOF pro mass spectrometer (Bruker Daltonics) with a modified nano electrospray ion source (CaptiveSpray, Bruker Daltonics). The system was calibrated each week and mass precision was greater than $1 \mathrm{ppm}$. A 1400 spray voltage with a capillary temperature of $180^{\circ} \mathrm{C}$ was typically employed for ionizing. MS spectra were acquired in the positive mode in the mass range from 100 to $1700 \mathrm{~m} / \mathrm{z}$. In the experiments described here, the mass spectrometer was operated in PASEF mode with exclusion of single charged peptides. A number of 10 PASEF MS/MS scans was performed during 1.25 seconds from charge range 2-5.

\subsubsection{Peptide Sequencing and Protein Precursor Identification}

The fragmentation pattern was used to determine the sequence of the peptide. Database searching was performed using the Peaks $\mathrm{X}$ software. A custom database was used, consisting in the translated sequences of loci from the digestive gland transcriptome of the Manila clam (unpublished data; a FASTA file containing loci sequences for significantly differentially 
183 accumulated proteins can be sound in supplementary file 3, with the corresponding annotations in 184 supplementary file 2). The variable modifications allowed were as follows: C-Carbamidomethyl, 185 K-acetylation, methionine oxidation, and Deamidation (NQ). "Trypsin" was selected as 186 Semispecific. Mass accuracy was set to $30 \mathrm{ppm}$ and $0.05 \mathrm{Da}$ for MS and MS/MS mode 187 respectively. Data were filtering according to a FDR of $0.5 \%$ and the elimination of protein 188 redundancy on the basis of proteins being evidenced by the same set or a subset of peptides.

191 Label-free quantitative data from Peaks X software were imported into Perseus in which 192 statistical analyses were performed [31]. Data were $\log 2$-transformed and only proteins 193 identified in every sample of at least one of the conditions tested were kept for further analysis. 194 Data were then compared using a t-test between conditions "RES" and "DIS", a threshold of 195 significance of 0.05 was applied, below which proteins were considered as statistically 196 differentially accumulated. 


\section{RESULTS AND DISCUSSION}

199

200

201

202

203

204

205

206

207

208

209

210

211

212

213

214

215

216

217

218

219

220

221

222

223

224

225

226

227

228

\subsection{Identification of RES vs DIS individuals following experimental infection}

A major goal of this study was to compare the proteomic changes in $R$. philippinarum individuals, from a single population, showing contrasted susceptibilities to BRD. Overall, a low mortality of $2.4 \%$ was observed during the four-week incubation period, as it often observed when $V$. tapetis is injected into the pallial fluids. Moreover, this low mortality occurred mostly on days 5-6, as was previously described by authors which suggested this is due to septicemia following accidental injections of $V$. tapetis in the tissues [32]. The highest mortality per group (5.5\%) occurred in group C1 (inoculated with FSSW), whereas group C2 (no treatment) and the experimental group (inoculated with $V$. tapetis) showed $1.8 \%$ and $1.9 \%$ total mortality, respectively, comparable to the results obtained in other BRD studies [13]. Shell length $(12.37 \pm 0.14 \mathrm{~mm})$ and total weight $(0.411 \pm 0.011 \mathrm{~g})$ were measured for all individuals, and dual diagnosis was carried out for 430 experimental clams. Dual diagnosis of the experimental clams showed that $59 \%$ showed varying degrees of conchiolin deposits, and $42 \%$ were PCR-positive for the strain-specific virB4 173 bp amplicon. Overall, the experimental population was relatively evenly distributed in the four categories (Table 1). Control groups C1 $(n=66)$ and C2 $(n=49)$ showed conchiolin deposits in $1.5 \%$ and $2 \%$ of individuals, respectively, and none of the control samples were positive for molecular diagnosis.

The four diagnostic categories in which the experimental clams were placed represent four stages in the infection process as it occurs within the extra pallial compartment, summarized in Figure 1. Clams from the two extreme phenotypes, i.e. category 0 (BRD-/PCR-) and category 3 (BRD+/PCR+), were chosen for the following proteomic study.

\subsection{Differential shotgun proteomics of resistant (RES) vs diseased (DIS) clams}

In all, we could identify 2093 proteins, of which 2021 were present in at least 2 out of 3 samples in one or both condition(s) (termed "RES" for category 0/resistant and "DIS" for category 3/diseased). Only proteins identified in both RES and DIS samples were retained for downstream analyses. Spectral counts were used to calculate the relative abundance of proteins. A Student Ttest was used to identify proteins for which abundance was significantly modified in either of the 
229 two categories, yielding a list of 102 proteins significantly more abundant in either RES or DIS

230 clams ( $p$-val $<0.05$; a complete list of these proteins can be found in the supplementary file 2,

231 and a FASTA file containing the corresponding sequences of the loci can be found in

232 supplementary file 3). Of these, 49 proteins had a fold-change of at least 1.5: seventeen proteins

233 were accumulated in the RES group and thirty-two proteins in the DIS group, four of which could

234 not be characterized (C. gigas protein IDs: EKC23703, EKC34161, EKC41442, EKC37917).

235 These 49 proteins are presented in Figure 2 and their annotations are further detailed in Table 2;

236 they were functionally annotated by examining their associated COG categories, biological

237 process GO terms, and literature review, and discussed below according to their potential roles in

238 different aspects of Brown Ring disease, i.e. the "Immune response", "Energy production" and

239 "Protein metabolism".

Table 1: Dual diagnosis through visual inspection of the inner surface of both valves (BRD+ or BRD-) and PCR amplification of the virB4 gene region of $173 \mathrm{bp}$ (PCR+ or PCR-) allows for distinction between 4 categories, ranging from CAT 0 (uninfected post-challenge, termed "RES") to CAT 3 (infected according to both diagnostic methods, termed "DIS"). The 430 samples tested show that $24 \%$ and $26 \%$ of samples fall in CAT 0 and CAT 3 , respectively. The link between these categories and the kinetics of infection in the extra pallial compartment with Vibrio tapetis is described in Figure 1.

DIAGNOSTIC CATEGORIES:

\begin{tabular}{c|c|c}
$\begin{array}{c}\text { Total experimental } \\
\text { clams } n=430\end{array}$ & BRD- & BRD+ \\
\hline PCR- & $\begin{array}{c}\text { CAT 0 } \\
n=105 ; 24 \%\end{array}$ & $\begin{array}{c}\text { CAT 2 } \\
n=142 ; 33 \%\end{array}$ \\
\hline PCR+ & $\begin{array}{c}\text { CAT 1 } \\
n=70 ; 16 \%\end{array}$ & $\begin{array}{c}\text { CAT 3 } \\
n=113 ; 26 \%\end{array}$
\end{tabular}


(a)

(b)

(c)

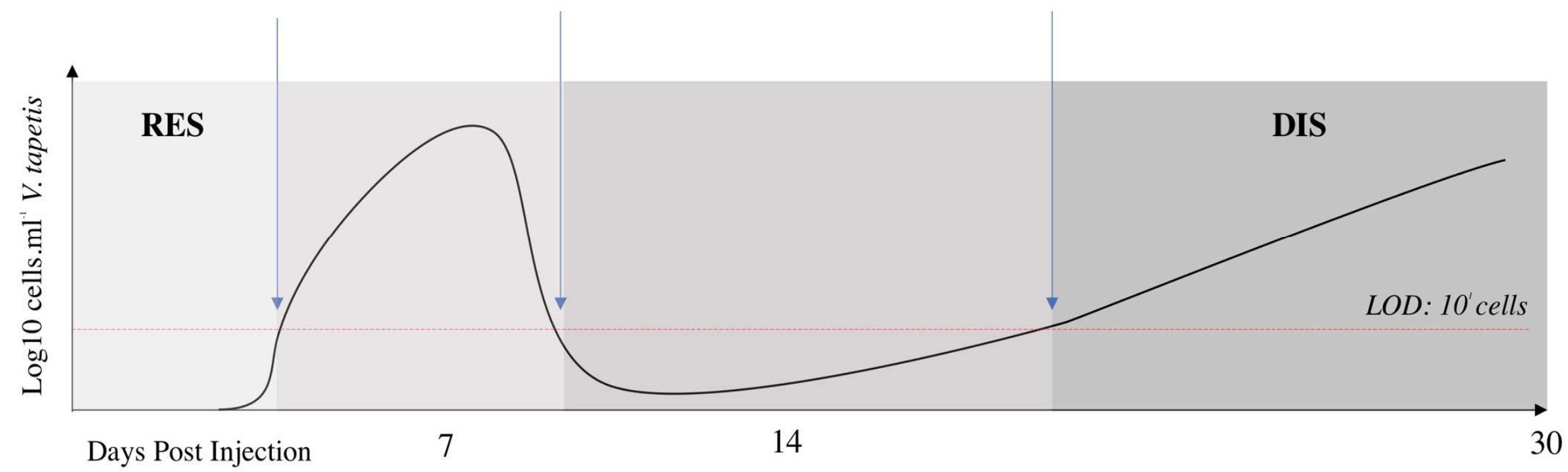

(ad. Bidault et al. 2015)

Figure 1: Schematic representation of the kinetics of Brown ring disease development during 30 days post injection (DPI) in a controlled challenge, adapted from Bidault et al. 2015, showing concentration of V. tapetis in extrapallial fluids (cells. $\mathrm{mL}^{-1}$ ) and limit of detection (LOD) at 1x10 ${ }^{1}$ cells. "RES" clams are negative for both visual and molecular diagnosis. Bacteria enter the extrapallial compartment and become quantifiable at point (a), then proliferate rapidly (clams at this stage are termed "CAT 1" in our study), with highest concentrations generally observed around 7 DPI. The host then begins to trap the bacteria within the conchiolin deposits characteristic of Brown ring disease, thus leading to a decrease in the concentration of bacteria in the extrapallial compartment (clams at this stage are termed "CAT 2" in our study), represented by point (b). Clams can thus be positive for the visual diagnosis and negative for molecular diagnosis whilst the bacteria remain trapped against the inner surface of the shell, a process during which the host attempts to recalcify over the bacterial biofilm. In the case of "DIS" clams, conchiolin deposits are present but insufficient in limiting the pathogen, which will continue to proliferate (point (c), also termed "CAT 3" for this study) and reach high concentrations in the extrapallial compartment once more. 
Disribution of significantly abundant proteins $(\mathrm{FC}>1.5)$ in resistant ("RES") and diseased ("DIS") clams, by functional groups.

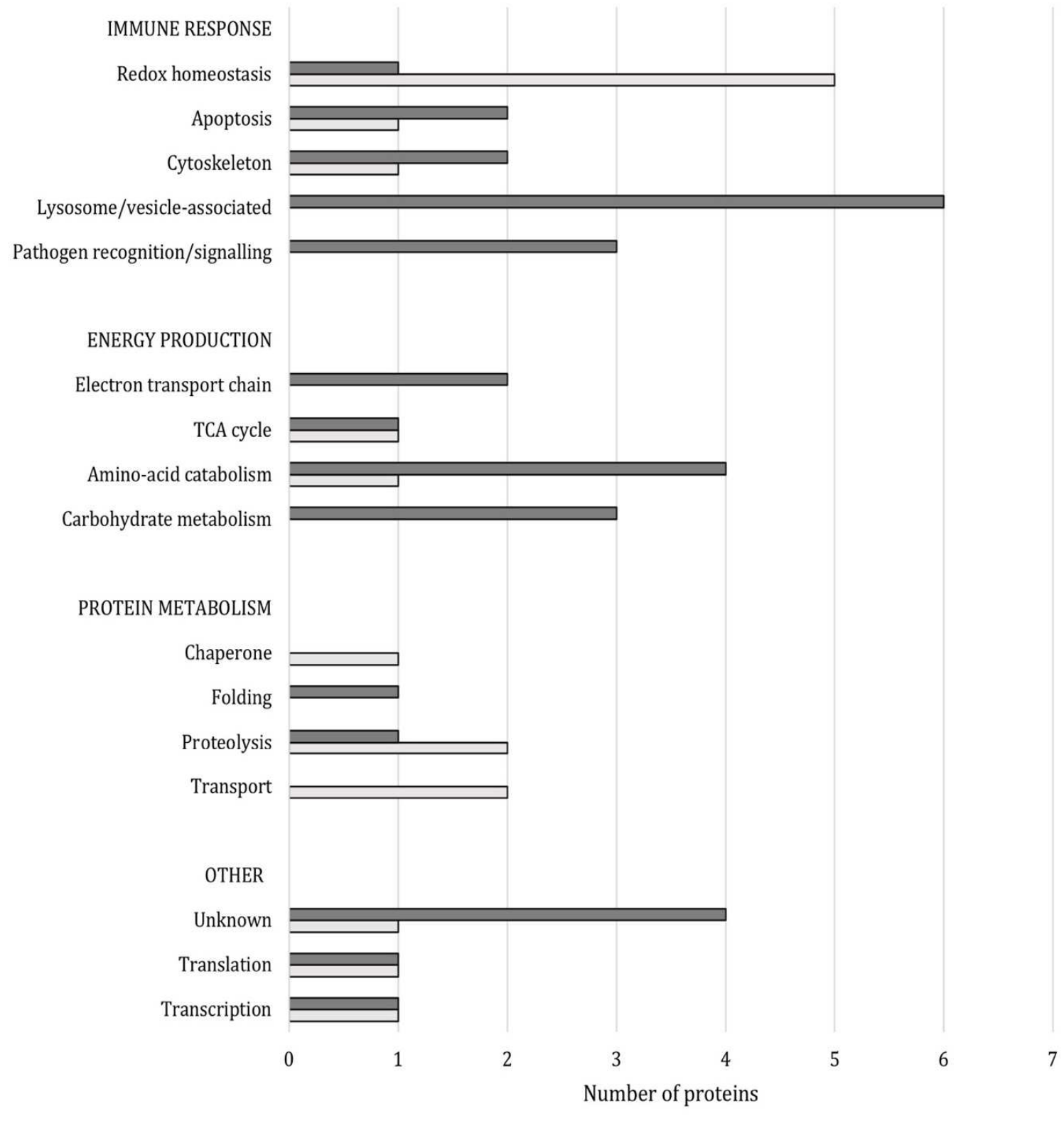

口DIS QRES

Figure 2: Number of proteins per functional group (i.e. "immune response", "energy production”, "protein metabolism") that were more abundant in DIS clams (dark bars) and in RES clams (light bars). 
Table 2: Proteins significantly abundant (p-val < 0.05) in DIS and RES clams, with fold-change > 1.5 ("group ratio"). Based on Clusters of Orthogous Groups (COG), Biological Process GO terms, and literature review regarding the roles of these proteins in the context of disease, the proteins are grouped into three main functional roles described in the discussion; "Immune response", "Energy production", and "Protein metabolism".

\begin{tabular}{|c|c|c|c|c|c|c|c|c|c|c|c|}
\hline $\begin{array}{c}\text { DIS } \\
\text { Intensity }\end{array}$ & $\begin{array}{c}\text { RES } \\
\text { Intensity }\end{array}$ & $\begin{array}{l}\text { Group } \\
\text { Ratio }^{+}\end{array}$ & $\begin{array}{l}\text { Student's } \\
\text { T-test p- } \\
\text { value } \\
\end{array}$ & $\begin{array}{l}\text { Unique } \\
\text { peptides }\end{array}$ & $\begin{array}{l}\text { R. philippinarum } \\
\text { locus ID }\end{array}$ & C. gigas protein ID & $\begin{array}{c}\text { Protein } \\
\text { name }\end{array}$ & $\mathrm{COG}$ & C. gigas gene description & $\begin{array}{l}\text { Biological process GO } \\
\text { term }\end{array}$ & $\begin{array}{c}\text { Functional role } \\
\text { discussed }\end{array}$ \\
\hline 1440 & 948 & $1.51: 1.00$ & 0.002 & 3 & Locus 6868673 & EKC40501 & LGALS9 & $\mathrm{W}$ & Galectin-9 & $\begin{array}{c}\text { GO:0006954 } \\
\text { inflammatory response }\end{array}$ & $\begin{array}{c}\text { Immune } \\
\text { response - } \\
\text { pathogen } \\
\text { recognition } \\
\end{array}$ \\
\hline 1250 & 421 & $2.97: 1.00$ & 0.041 & 1 & Locus 5288240 & EKC31577 & BGBP & G & $\begin{array}{l}\text { Beta-1,3-glucan-binding } \\
\text { protein } 1\end{array}$ & $\begin{array}{c}\text { GO:0002752 cell surface } \\
\text { pattern recognition } \\
\text { receptor signaling } \\
\text { pathway }\end{array}$ & $\begin{array}{l}\text { Immune } \\
\text { response - } \\
\text { pathogen } \\
\text { recognition } \\
\end{array}$ \\
\hline 384 & 244 & $1.57: 1.00$ & 0.026 & 1 & Locus 4334179 & EKC24393 & $\mathrm{C} 3$ & $\mathrm{O}$ & Complement C3 & $\begin{array}{l}\text { GO:0006955 immune } \\
\text { response }\end{array}$ & $\begin{array}{c}\text { Immune } \\
\text { response - } \\
\text { signalling } \\
\end{array}$ \\
\hline 647 & 1770 & $2.73: 1.00$ & 0.005 & 3 & Locus 615620 & EKC23268 & IQGAP1 & $\mathrm{Z}$ & $\begin{array}{l}\text { Ras GTPase-activating- } \\
\text { like protein }\end{array}$ & $\begin{array}{l}\text { GO: } 1903829 \text { positive } \\
\text { regulation of cellular } \\
\text { protein localization }\end{array}$ & $\begin{array}{l}\text { Immune } \\
\text { response - } \\
\text { cytoskeleton }\end{array}$ \\
\hline 1270 & 832 & $1.53: 1.00$ & 0.025 & 3 & Locus 2955238 & EKC27178 & DCTN2 & $\mathrm{Z}$ & Dynactin subunit 2 & $\begin{array}{l}\text { GO:0006888 endoplasmic } \\
\text { reticulum to Golgi vesicle- } \\
\text { mediated transport }\end{array}$ & $\begin{array}{c}\text { Immune } \\
\text { response - } \\
\text { cytoskeleton } \\
\end{array}$ \\
\hline 14900 & 4540 & $3.29: 1.00$ & 0.018 & 9 & Locus 7235177 & EKC29122 & $\mathrm{SCP}$ & $\mathrm{S}$ & $\begin{array}{l}\text { Sarcoplasmic calcium- } \\
\text { binding protein }\end{array}$ & $\begin{array}{l}\text { GO: } 0051480 \text { regulation of } \\
\text { cytosolic calcium ion } \\
\text { concentration }\end{array}$ & $\begin{array}{l}\text { Immune } \\
\text { response - } \\
\text { cytoskeleton }\end{array}$ \\
\hline 3200 & 2010 & $1.59: 1.00$ & 0.025 & 4 & Locus 2215912 & EKC27269 & CPVL & $\mathrm{O}$ & $\begin{array}{c}\text { Putative serine } \\
\text { carboxypeptidase CPVL }\end{array}$ & $\begin{array}{c}\text { GO:0051603 proteolysis } \\
\text { involved in cellular } \\
\text { protein catabolic process }\end{array}$ & $\begin{array}{l}\text { Immune } \\
\text { response - } \\
\text { lysosomal }\end{array}$ \\
\hline 910 & 486 & $1.87: 1.00$ & 0.005 & 1 & Locus 2384090 & EKC25290 & EPDR1 & $\mathrm{S}$ & ependymin related 1 & $\begin{array}{c}\text { GO:0007160 cell-matrix } \\
\text { adhesion }\end{array}$ & $\begin{array}{l}\text { Immune } \\
\text { response - } \\
\text { lysosomal }\end{array}$ \\
\hline 903 & 446 & $2.03: 1.00$ & 0.045 & 1 & Locus 2964637 & EKC26355 & OVCH1 & $\mathrm{O}$ & Ovochymase-1 & GO:0006508 proteolysis & $\begin{array}{l}\text { Immune } \\
\text { response - } \\
\text { lysosomal }\end{array}$ \\
\hline 2660 & 531 & $5.02: 1.00$ & 0.029 & 2 & Locus 3062641 & ENSDARP00000139466* & PPT1 & $\mathrm{S}$ & $\begin{array}{l}\text { palmitoyl-protein } \\
\text { thioesterase } 1\end{array}$ & $\begin{array}{l}\text { GO:0007042 lysosomal } \\
\text { lumen acidification }\end{array}$ & $\begin{array}{l}\text { Immune } \\
\text { response - } \\
\text { lysosomal }\end{array}$ \\
\hline 680 & 374 & $1.82: 1.00$ & 0.014 & 1 & Locus 665720 & EKC31469 & RAB43 & $\mathrm{U}$ & $\begin{array}{l}\text { Ras-related protein Rab- } \\
\qquad 43\end{array}$ & $\begin{array}{c}\text { GO:0090382 phagosome } \\
\text { maturation }\end{array}$ & $\begin{array}{l}\text { Immune } \\
\text { response - } \\
\text { vesicles }\end{array}$ \\
\hline
\end{tabular}




\begin{tabular}{|c|c|c|c|c|c|c|c|c|c|c|c|}
\hline 1780 & 716 & 2.49:1.00 & 0.027 & 6 & Locus 2853765 & EKC32573 & VPS35 & $\mathrm{U}$ & $\begin{array}{l}\text { Vacuolar protein sorting- } \\
\text { associated protein } 35\end{array}$ & $\begin{array}{c}\text { GO:0007040 lysosome } \\
\text { organization }\end{array}$ & $\begin{array}{l}\text { Immune } \\
\text { response - } \\
\text { vesicles }\end{array}$ \\
\hline 296 & 2550 & $8.61: 1.00$ & 0.003 & 3 & Locus 6888709 & EKC26119 & $\mathrm{ACE}$ & $\mathrm{C}$ & $\begin{array}{c}\text { Angiotensin-converting } \\
\text { enzyme }\end{array}$ & $\begin{array}{l}\text { GO: } 0001817 \text { regulation of } \\
\text { cytokine production }\end{array}$ & $\begin{array}{c}\text { Immune } \\
\text { response - redox } \\
\end{array}$ \\
\hline 323 & 669 & $2.07: 1.00$ & 0.019 & 1 & Locus 2057997 & EKC35339 & TXNDC5 & $\mathrm{O}$ & $\begin{array}{l}\text { Thioredoxin domain- } \\
\text { containing protein } 5\end{array}$ & $\begin{array}{c}\text { GO:0045454cell redox } \\
\text { homeostasis }\end{array}$ & $\begin{array}{c}\text { Immune } \\
\text { response - redox }\end{array}$ \\
\hline 4480 & 8140 & $1.82: 1.00$ & 0.045 & 3 & Locus 355976 & ЕКC36585 & $\mathrm{ACE}$ & $\mathrm{E}$ & $\begin{array}{l}\text { Angiotensin-converting } \\
\text { enzyme }\end{array}$ & $\begin{array}{l}\text { GO:0001817 regulation of } \\
\text { cytokine production }\end{array}$ & $\begin{array}{c}\text { Immune } \\
\text { response - redox }\end{array}$ \\
\hline 152 & 245 & $1.61: 1.00$ & 0.048 & 1 & Locus 4589062 & EKC37227 & ADH5 & Q & $\begin{array}{c}\text { Alcohol dehydrogenase } \\
\text { class-3 }\end{array}$ & $\begin{array}{c}\text { GO:0051775 response to } \\
\text { redox state }\end{array}$ & $\begin{array}{c}\text { Immune } \\
\text { response - redox }\end{array}$ \\
\hline 399 & 638 & $1.60: 1.00$ & 0.036 & 1 & Locus 2688502 & ЕКC36531 & $\mathrm{XDH}$ & $\mathrm{F}$ & $\begin{array}{c}\text { Xanthine } \\
\text { dehydrogenase/oxidase }\end{array}$ & $\begin{array}{l}\text { GO:2000379 positive } \\
\text { regulation of reactive } \\
\text { oxygen species metabolic } \\
\text { process }\end{array}$ & $\begin{array}{c}\text { Immune } \\
\text { response - redox }\end{array}$ \\
\hline 2250 & 783 & $2.87: 1.00$ & 0.006 & 2 & Locus 6590720 & EKC20036 & GPX3 & $\mathrm{O}$ & Glutathione peroxidase & $\begin{array}{c}\text { GO:0034599 cellular } \\
\text { response to oxidative } \\
\text { stress } \\
\end{array}$ & $\begin{array}{c}\text { Immune } \\
\text { response - redox }\end{array}$ \\
\hline 448 & 753 & $1.68: 1.00$ & 0.003 & 2 & Locus 3201607 & EKC33267 & SH3GLB1 & $\mathrm{T}$ & Endophilin-B1 & $\begin{array}{c}\text { GO:0006915 apoptotic } \\
\text { process }\end{array}$ & $\begin{array}{c}\text { Immune } \\
\text { response - } \\
\text { apoptosis } \\
\end{array}$ \\
\hline 1030 & 593 & $1.73: 1.00$ & 0.007 & 1 & Locus 1202748 & EKC29685 & PPP3CC & $\mathrm{T}$ & $\begin{array}{c}\text { Serine/threonine-protein } \\
\text { phosphatase }\end{array}$ & $\begin{array}{c}\text { GO:0035970 peptidyl- } \\
\text { threonine } \\
\text { dephosphorylation }\end{array}$ & $\begin{array}{c}\text { Immune } \\
\text { response - } \\
\text { apoptosis }\end{array}$ \\
\hline 749 & 351 & $2.13: 1.00$ & 0.002 & 2 & Locus 1979842 & EKC21473 & CECR1 & $\mathrm{F}$ & $\begin{array}{l}\text { Adenosine deaminase } \\
\text { CECR } 1\end{array}$ & $\begin{array}{l}\text { GO:0006154 adenosine } \\
\text { catabolic process }\end{array}$ & $\begin{array}{c}\text { Immune } \\
\text { response - } \\
\text { apoptosis } \\
\end{array}$ \\
\hline 3500 & 2120 & $1.65: 1.00$ & 0.036 & 1 & Locus 1236277 & EKC20480 & AGL & G & $\begin{array}{l}\text { Glycogen debranching } \\
\text { enzyme }\end{array}$ & $\begin{array}{l}\text { GO: } 0005980 \text { glycogen } \\
\text { catabolic process }\end{array}$ & $\begin{array}{c}\text { Energy } \\
\text { production - } \\
\text { carbohydrate } \\
\text { metabolism } \\
\end{array}$ \\
\hline 2860 & 1720 & $1.67: 1.00$ & 0.007 & 3 & Locus 8380444 & EKC18570 & PGM1 & G & Phosphoglucomutase-1 & $\begin{array}{l}\text { GO:0006006 glucose } \\
\text { metabolic process }\end{array}$ & $\begin{array}{c}\text { Energy } \\
\text { production - } \\
\text { carbohydrate } \\
\text { metabolism } \\
\end{array}$ \\
\hline 11100 & 6930 & $1.60: 1.00$ & 0.037 & 7 & Locus 381335 & EKC27095 & PCK2 & $\mathrm{C}$ & $\begin{array}{l}\text { Phosphoenolpyruvate } \\
\text { carboxykinase [GTP] }\end{array}$ & $\begin{array}{l}\text { GO:0006094 } \\
\text { gluconeogenesis }\end{array}$ & $\begin{array}{c}\text { Energy } \\
\text { production - } \\
\text { carbohydrate } \\
\text { metabolism } \\
\end{array}$ \\
\hline 1130 & 1770 & $1.57: 1.00$ & 0.031 & 2 & Locus 2128190 & EKC32958 & AUH & I & $\begin{array}{l}\text { Methylglutaconyl-CoA } \\
\text { hydratase }\end{array}$ & $\begin{array}{l}\text { GO:0006552 leucine } \\
\text { catabolic process }\end{array}$ & $\begin{array}{c}\text { Energy } \\
\text { production - } \\
\text { AAs }\end{array}$ \\
\hline 581 & 298 & $1.95: 1.00$ & 0.013 & 1 & Locus 2982362 & EKC42273 & SLC1A1 & $\mathrm{E}$ & $\begin{array}{l}\text { Excitatory amino acid } \\
\text { transporter } 1\end{array}$ & $\begin{array}{l}\text { GO:0006537 glutamate } \\
\text { biosynthetic process }\end{array}$ & $\begin{array}{c}\text { Energy } \\
\text { production - } \\
\text { AAs }\end{array}$ \\
\hline
\end{tabular}




\begin{tabular}{|c|c|c|c|c|c|c|c|c|c|c|c|}
\hline 6150 & 1990 & $3.09: 1.00$ & 0.041 & 10 & Locus 8587681 & EKC33186 & GPT2 & $\mathrm{E}$ & $\begin{array}{l}\text { Alanine aminotransferase } \\
2\end{array}$ & $\begin{array}{l}\text { GO:0042851 L-alanine } \\
\text { metabolic process }\end{array}$ & $\begin{array}{c}\text { Energy } \\
\text { production - } \\
\text { AAs } \\
\end{array}$ \\
\hline 21400 & 6060 & $3.54: 1.00$ & 0 & 19 & Locus 2044774 & EKC40669 & GOT1 & $\mathrm{E}$ & $\begin{array}{c}\text { Aspartate } \\
\text { aminotransferase, } \\
\text { cytoplasmic }\end{array}$ & $\begin{array}{l}\text { GO:0006107 oxaloacetate } \\
\text { metabolic process }\end{array}$ & $\begin{array}{c}\text { Energy } \\
\text { production - } \\
\text { AAs } \\
\end{array}$ \\
\hline 4660 & 2820 & $1.65: 1.00$ & 0.034 & 1 & Locus 7730822 & EKC43060 & $\mathrm{PCCB}$ & EI & $\begin{array}{l}\text { Propionyl-CoA } \\
\text { carboxylase beta chain }\end{array}$ & $\begin{array}{l}\text { GO:0006552 leucine } \\
\text { catabolic process }\end{array}$ & $\begin{array}{c}\text { Energy } \\
\text { production - } \\
\text { AAs } \\
\end{array}$ \\
\hline 9940 & 24000 & $2.41: 1.00$ & 0.038 & 8 & Locus 4823168 & EKC21276 & PDHA1 & $\mathrm{C}$ & $\begin{array}{l}\text { Pyruvate dehydrogenase } \\
\text { E1 subunit alpha }\end{array}$ & $\begin{array}{c}\text { GO:0006086 acetyl-CoA } \\
\text { biosynthetic process from } \\
\text { pyruvate }\end{array}$ & $\begin{array}{l}\text { Energy } \\
\text { production - } \\
\text { TCA }\end{array}$ \\
\hline 38700 & 24600 & $1.57: 1.00$ & 0.001 & 26 & Locus 2348137 & EKC25158 & MDH1 & $\mathrm{C}$ & Malate dehydrogenase & $\begin{array}{c}\text { GO:0006099 tricarboxylic } \\
\text { acid cycle }\end{array}$ & $\begin{array}{l}\text { Energy } \\
\text { production - } \\
\text { TCA }\end{array}$ \\
\hline 1120 & 662 & $1.69: 1.00$ & 0.026 & 1 & Locus 5269440 & EKC19854 & REBM & I & $\begin{array}{l}\text { 3-demethylubiquinone-9 } \\
\text { 3-methyltransferase }\end{array}$ & $\begin{array}{l}\text { GO:0006744 ubiquinone } \\
\text { biosynthetic process }\end{array}$ & $\begin{array}{l}\text { Energy } \\
\text { production - } \\
\text { ETC }\end{array}$ \\
\hline 42700 & 24200 & $1.77: 1.00$ & 0.041 & 34 & Locus 4313121 & EKC39329 & AIPS & $\mathrm{C}$ & $\begin{array}{l}\text { ATP synthase subunit } \\
\text { alpha }\end{array}$ & $\begin{array}{c}\text { GO:0006754 ATP } \\
\text { biosynthetic process }\end{array}$ & $\begin{array}{c}\text { Energy } \\
\text { production - } \\
\text { ETC } \\
\end{array}$ \\
\hline 1190 & 2290 & $1.92: 1.00$ & 0.049 & 3 & Locus 1397283 & EKC35325 & TTN & $\mathrm{T}$ & Titin & GO:0007155 cell adhesion & $\begin{array}{c}\text { Protein } \\
\text { metabolism - } \\
\text { transport }\end{array}$ \\
\hline 1940 & 2980 & $1.54: 1.00$ & 0.041 & 3 & Locus 5145028 & EKC29146 & YWHAE & $\mathrm{O}$ & 14-3-3 protein epsilon & $\begin{array}{l}\text { GO:0035556 intracellular } \\
\text { signal transduction }\end{array}$ & $\begin{array}{l}\text { Protein } \\
\text { metabolism - } \\
\text { transport }\end{array}$ \\
\hline 1600 & 3590 & $2.24: 1.00$ & 0.034 & 10 & Locus 3208485 & EKC19309 & CAND1 & $\mathrm{S}$ & $\begin{array}{c}\text { Cullin-associated } \\
\text { NEDD8-dissociated } \\
\text { protein } 1\end{array}$ & $\begin{array}{l}\text { GO:0016567 protein } \\
\text { ubiquitination }\end{array}$ & $\begin{array}{l}\text { Protein } \\
\text { metabolism-- } \\
\text { proteolysis }\end{array}$ \\
\hline 498 & 1630 & $3.27: 1.00$ & 0.044 & 2 & Locus 4231109 & EKC28114 & PSMC1 & $\mathrm{O}$ & $\begin{array}{l}\text { 26S proteasome non- } \\
\text { ATPase regulatory } \\
\text { subunit } 7\end{array}$ & $\begin{array}{l}\text { GO:0000209 protein } \\
\text { polyubiquitination }\end{array}$ & $\begin{array}{c}\text { Protein } \\
\text { metabolism - } \\
\text { proteolysis }\end{array}$ \\
\hline 440 & 235 & $1.88: 1.00$ & 0.035 & 1 & Locus 4900110 & EKC29780 & PSMD7 & $\mathrm{O}$ & $\begin{array}{c}26 \mathrm{~S} \text { protease regulatory } \\
\text { subunit } 4\end{array}$ & $\begin{array}{l}\text { GO:0000209 protein } \\
\text { polyubiquitination }\end{array}$ & $\begin{array}{l}\text { Protein } \\
\text { metabolism - } \\
\text { proteolysis }\end{array}$ \\
\hline 4860 & 2510 & $1.94: 1.00$ & 0.012 & 4 & Locus 2922613 & EKC25378 & FKBP14 & $\mathrm{O}$ & $\begin{array}{l}\text { FK506 binding protein } \\
14\end{array}$ & $\begin{array}{l}\text { GO:0046716 muscle cell } \\
\text { cellular homeostasis }\end{array}$ & $\begin{array}{c}\text { Protein } \\
\text { metabolism - } \\
\text { protein folding }\end{array}$ \\
\hline 2550 & 4140 & $1.62: 1.00$ & 0.014 & 16 & Locus 2939806 & EKC25687 & HSP90AB1 & $\mathrm{O}$ & $\begin{array}{c}\text { Heat shock protein HSP } \\
90 \text {-alpha } 1\end{array}$ & $\begin{array}{l}\text { GO:0050821 protein } \\
\text { stabilization }\end{array}$ & $\begin{array}{l}\text { Protein } \\
\text { metabolism - } \\
\text { chaperone }\end{array}$ \\
\hline
\end{tabular}




\begin{tabular}{|c|c|c|c|c|c|c|c|c|c|c|c|}
\hline 633 & 1200 & $1.90: 1.00$ & 0.048 & 2 & Locus 2389731 & EKC42074 & РCBP3 & A & $\begin{array}{l}\text { Poly(RC)-binding protein } \\
3\end{array}$ & $\begin{array}{l}\text { GO:0000122 negative } \\
\text { regulation of transcription } \\
\text { by RNA polymerase II }\end{array}$ & $\begin{array}{l}\text { Other - } \\
\text { transcription }\end{array}$ \\
\hline 1300 & 563 & $2.31: 1.00$ & 0.023 & 1 & Locus 995640 & EKC39351 & PURA & $\mathrm{K}$ & $\begin{array}{l}\text { Transcriptional activator } \\
\text { protein Pur-alpha }\end{array}$ & $\begin{array}{l}\text { GO:0006268 DNA } \\
\text { unwinding involved in } \\
\text { DNA replication }\end{array}$ & $\begin{array}{l}\text { Other - } \\
\text { transcription }\end{array}$ \\
\hline 1860 & 2940 & $1.58: 1.00$ & 0.003 & 1 & Locus 453724 & EKC20816 & NARS & $\mathrm{J}$ & $\begin{array}{l}\text { Asparaginyl-tRNA } \\
\text { synthetase }\end{array}$ & $\begin{array}{l}\text { GO:0006421 asparaginyl- } \\
\text { tRNA aminoacylation }\end{array}$ & $\begin{array}{l}\text { Other - } \\
\text { translation }\end{array}$ \\
\hline 1300 & 752 & $1.73: 1.00$ & 0.024 & 2 & Locus 454248 & EKC31246 & RPL27A & $\mathrm{J}$ & $\begin{array}{c}\text { 60S ribosomal protein } \\
\text { L27a }\end{array}$ & GO:0006412 translation & $\begin{array}{c}\text { Other - } \\
\text { translation }\end{array}$ \\
\hline 818 & 1560 & $1.91: 1.00$ & 0.021 & 2 & Locus 3238632 & EKC23703 & - & - & $\begin{array}{c}\text { Uncharacterized - } \\
\text { Calycin superfamily }\end{array}$ & $-\cdots$ & Other - unknown \\
\hline 584 & 357 & $1.64: 1.00$ & 0.018 & 1 & Locus 4959443 & EKC41849 & ABHD14A & $S$ & $\begin{array}{l}\text { Abhydrolase domain- } \\
\text { containing protein 14A }\end{array}$ & $\begin{array}{c}\text { GO:0006656 } \\
\text { phosphatidylcholine } \\
\text { biosynthetic process }\end{array}$ & Other - unknown \\
\hline 670 & 396 & $1.69: 1.00$ & 0.033 & 1 & Locus 1004421 & EKC34161 & - & - & si:ch73-250a16.5 & - - - & Other - unknown \\
\hline 3520 & 1910 & $1.85: 1.00$ & 0.042 & 6 & Locus 6596965 & EKC41442 & & - & $\begin{array}{c}\text { Uncharacterized - SH3- } \\
\text { like domain }\end{array}$ & -- & Other - unknown \\
\hline 1060 & 350 & $3.03: 1.00$ & 0.028 & 3 & Locus 4498780 & EKC37917 & - & - & $\begin{array}{c}\text { Uncharacterized - } \\
\text { Carbohydrate esterase } 4 \\
\text { (CE4) family }\end{array}$ & -- & Other - unknown \\
\hline
\end{tabular}




\subsection{IMMUNE RESPONSE-ASSOCIATED PROTEINS}

\subsubsection{Pathogen recognition and immune-pathway activation}

The ongoing infection process in clams from the DIS group is supported by the presence of a number of proteins whose primary functions are associated with pathogen recognition and the subsequent triggering of signaling pathways, such as Galectin-9 (Gal9), 1-3- $\beta$-glucan-binding protein (BGBP), and Complement component C3 (C3). Proteins such as Galectins, which have previously been demonstrated as upregulated in the extra pallial fluids of $V$. tapetis-infected clams, and BGBP act as pattern recognition receptors (PRRs) by recognizing $\beta$-galactoside and lipopolysaccharide residues found on bacterial membranes [18,33,34]. This initiates the immune response by activating signaling pathways for chemotaxis, phagocytosis, and opsonization and induces antimicrobial peptide (AMP) synthesis through the prophenoloxidase and complement cascade systems [35,36]. Interestingly, selective breeding for parasite resistance in the Sydney rock oyster found that resistance was directly related to the loss of a specific form of phenoloxidase enzymes, supporting the presence of this particular enzyme as a marker of susceptibility [37,38]. The C3 protein identified in our dataset belongs to the complement cascade system, an essential component of the invertebrate immune response leading to the opsonization and lysis of pathogens [39-42]. Upregulation of proteins associated to the complement system have previously been described in $R$. philippinarum through several transcriptomic studies investigating response to disease, highlighting the importance of this pathway in host response to Vibrio pathogens $[18,24]$. The significantly high abundance of proteins specifically involved in pathogen recognition in the DIS group supports a strong acute response to the ongoing infection with $V$. tapetis in these animals.

Interestingly, the RES clam group showed high abundance of Ras GTPase-activating-like protein 1 (IQGAP1), a pathway-activating protein that is implicated in a number of immune-associated functions. Namely, during infection by microbial pathogens that target the host microtubule network, similar to the way in which $V$. tapetis inhibits pseudopod formation in the hemocytes of $R$. philippinarum, IQGAP1 has been shown to bind to and modulate the activity of proteins involved in bacterial invasion, ultimately interacting with the actin cytoskeleton $[19,43]$. 


\subsubsection{Pathogen-associated lysosomal activity}

275 Other proteins highly abundant in the DIS group are involved in immune response through antimicrobial and lysosomal activity. The putative serine carboxypeptidase (CPLV) and the serine protease Ovochymase $(\mathrm{OVCH} 1)$ identified in the DIS group are known to have antibacterial activity and can be involved in proteolytic digestion of lysosomal components $[44,45]$. As lysosomes contain the hydrolytic enzymes necessary for degradation of cellular components as well as encapsulated pathogenic agents, it is also interesting to note the higher abundance of Ependymin-related protein 1 (EPDR1) in DIS samples, which has been suggested to function as a lysosomal activator protein, and Palmitoyl-protein thioesterase-1 (PPT1), which is associated with lysosomal degradation of proteins [46,47]. An uncharacterized protein in the DIS clam group belonging to the carbohydrate esterase 4 (CE4) family may also play a role in degrading phagocytosed bacteria as well as inhibiting biofilm formation, as certain enzymes of the CE4 family, whose main function is to de-acetylate polysaccharides, specifically degrade the essential peptidoglycan polymers of bacterial cell walls [48]. In addition, active intracellular membrane trafficking (ex. phagosomes) in DIS clams is suggested by the high abundance of proteins such as the Ras-related protein RAB43, which regulates vesicular movement following immune system activation by microbial infections, and a vacuolar-sorting protein VPS35, which directs transmembrane cargo proteins to the lysosomal degradation pathway $[49,50]$.

\subsubsection{Cytoskeleton-associated immune response}

294 The cytoskeleton is a network of filaments that plays an essential role in certain aspects of 295 immunity through cell structure maintenance, transport, phagocytosis, and communication 296 between cellular components. As such, it is also known to be one of the targets of invading 297 pathogens such as Perkinsus olseni and V. tapetis in the Manila clam [19,51,52]. Interestingly, a 298 dynactin subunit (DCTN2) and a sarcoplasmic calcium-binding protein (SCP) were highly 299 abundant in DIS clams, both of which play a role in cytoskeleton function. DCTN2 is part of a 300 dynein/dynactin complex which coordinates the microtubule movement of vacuoles towards 301 lysosomes and plays an important role in the biogenesis and transportation of pathogen302 containing vacuoles in rabbit cells infected by obligate intracellular bacteria [53,54]. This may 303 reflect the internalization of $V$. tapetis by hemocytes in the case of DIS clams, activating 304 microtubule motors such as the dynein/dynactin complex in an attempt to fuse bacteria- 
305

306

307

308

309

310

311

312

313

containing vacuoles with lysosomal membranes. SCPs, which are known to interact with the cytoskeleton by regulating the calcium balance, have been shown to be upregulated in Manila clam hemocytes in response to both parasitic and bacterial infections [18,22,51]. Bacteria of the genus Vibrio have been suggested to inhibit intracellular trafficking and the fusion of bacteriacontaining phagosomes with lysosomes in order to avoid neutralization, a relatively common immune-evasion technique seen in a number of pathologies [55]. In this light, the elevated abundance of lysosome-associated proteins in clams of the DIS group may reflect an attempt to counter the bacteria's inhibitory processes.

\subsubsection{Apoptotic processes}

Apoptosis of host immune cells during an infection can represent one of the ultimate defense strategies against invading pathogens, whereby the host cell is sacrificed so as to eliminate the internalized pathogenic agent [56]. Induction of apoptosis has been suggested to be one of the mechanisms of survival put in place by resistant oysters, Ostrea edulis, perhaps in response to anti-apoptotic mechanisms that are a known survival strategy for some intracellular pathogens, such as the protozoan parasite Bonamia ostreae [57]. Clams from the RES group in our study demonstrated higher abundances of Endophilin B1 (Bif-1), a protein associated with the formation of pores in the outer mitochondrial membrane that leads to apoptosis through the caspase pathway [57-59]. In contrast, DIS clams showed high abundance of adenosine deaminase (CECR1) a protein that, while primarily associated with the purine metabolism, also plays an important role in reducing the concentration of the toxic derivatives of adenosine and deoxyadenosine to protect cells from apoptosis $[60,61]$. A serine/threonine protein phosphatase PPP3CC, also more abundant in DIS clams, bears close resemblance with the protein phosphatase 3 catalytic subunit beta, PPP3CB, which was recently suggested to promote cell-proliferation and may play an anti-apoptotic role in tumorous human kidney cells [62]. While apoptosis is a complex process that can benefit immune defense, anti-apoptosis is also a mechanism by which the host may maintain cellular functions and continue combatting infection, though seemingly at a cost given the relatively high abundance of proteins involved in energy metabolism in the DIS clam group (see part 3.4).

\subsubsection{Redox homoeostasis}


336 Host production of reactive oxygen species (ROS) and reactive nitrogen species (RNS) is a

337 known mechanism of defense and pathogen neutralization, though this process requires a delicate

338 balance as the accumulation of ROS/RNS can also lead to oxidative damage to the host [63].

339 Glutathione peroxidase (GPX3), a member of the cellular antioxidant system, was more abundant

340 in the DIS clam group. Interestingly, a previous studies on BRD-infected Manila clams reported a

341 decrease in enzymatic activity of GPX at $7 \mathrm{dpi}$, though the study did not measure enzyme

342 abundance nor activity at 30 dpi [21]. Oysters subjected to bacterial infection, however, have

343 shown an upregulation of glutathione peroxidase gene expression in pathogen-challenged larvae,

344 suggesting that GPX may be an indicator of oxidative stress that may have been occurring in DIS

345 clams from our study as a result of the ongoing antibacterial processes discussed in part 3.3.2

$346[21,64]$.

347 The RES clam group was characterized by a higher abundance of proteins more or less directly

348 associated with ROS/RNS production and scavenging. Thioredoxin domain-containing protein 5

349 (TXNDC5) is a member of the protein disulfide isomerase family whose expression has been

350 associated with oxidative stress and cellular pathology $[65,66]$. At least two shorter-term (max 7

351 days) studies have investigated the role of thioredoxin in response to $V$. tapetis, pointing towards

352 an increase in activity of thioredoxin in $V$. tapetis-challenged clams compared to controls or to

353 resistant clams, thus the higher abundance of thioredoxin observed in RES clams of this study

354 may reflect a possible reversal of this mechanism in the case of long-term resistance (30 days)

355 [21,67]. Similarly, xanthine oxidoreductase (XOR), an enzyme implicated in the purine

356 metabolism, has previously been associated with a number of innate immunity processes

357 including redox homeostasis through the production of ROS and RNS by xanthine oxidase (XO),

358 as well as indirect free radical sequestration by xanthine dehydrogenase (XD) through the

359 synthesis the antioxidant uric acid [63,68-70]. RES clams also presented a significantly higher

360 abundance of two Angiotensin-converting enzymes (ACE), which were recently demonstrated to

361 induce superoxide production and thereby enhance bactericidal activity in mouse neutrophils

362 [71], and class-III alcohol dehydrogenase (ADH3). ADH3 uses the reducing power glutathione to

363 eliminate the organic compounds formaldehyde and S-nitrosothiols (SNO), ultimately limiting

364 their decomposition into the RNS nitric oxide [72,73]. Nitric oxide is a known toxic agent

365 produced by immune cells of invertebrates for pathogen defense, and NO production by $R$.

366 philippinarum in response to $V$. tapetis has been correlated to hemocyte rounding and pseudopod 
loss [74], highlighting the possible importance of NO-sequestration by proteins such as ADH3 in order to counter the negative effects of this compound on the host. These findings support previous hypotheses suggesting that ROS/RNS production by hemocytes may represent an alternative anti-bacterial response against pathogens such as $V$. tapetis, which is known to evade host immune responses such as phagocytosis by inhibiting pseudopod formation

$372[74,75]$. In addition, the higher abundance of the redox homeostasis-associated enzymes RES

373 clams supports findings from previous studies indicating that resistance may be associated with a 374 greater ability to balance ROS/RNS production and scavenging, allowing them to rapidly 375 neutralize pathogens before they are able to colonize the host while simultaneously protecting 376 host cells from oxidative damage, a dual process previously suggested using enzyme activity 377 assays in the Manila clam exposed to V. tapetis [21].

Proteins potentially associated with energy production through carbohydrate and amino acid catabolism represent the second largest group in our dataset, most of which (10 out of 12) are more abundant in the DIS clam group. This section groups together the proteins implicated in the degradation of glycogen and amino acids that generate essential metabolites for the tricarboxylic acid (TCA) cycle, leading to the production of high-energy electron donors such as NADH which can integrate the electron transport chain (Figure 3).

\subsubsection{Amino acid degradation for energy production}

389 Propionyl-CoA carboxylase beta chain (PCCB) and Methylglutaconyl-CoA hydratase (AUH), 390 enzymes involved in the degradation of branched-chain amino acids (BCAAs) such as leucine, 391 were significantly more abundant in DIS and RES clams, respectively. Demand for BCAAs as 392 energy metabolites or for the synthesis of immune-related molecules has been demonstrated to 393 increase during disease [76,77]. Decreased levels of a number of other amino acids during Vibrio 394 infection in mussels have also been reported, suggesting that the significantly higher abundance 395 of Alanine aminotransferase (GPT2), Aspartate aminotransferase (GOT1), and Excitatory amino396 acid transporter-1 (SLC1A1) in DIS clams may also be associated with the degradation and/or 
conversion of amino acids into metabolites such as pyruvate, oxaloacetate, and $\alpha$-ketoglutarate for the TCA cycle [78-81].

\subsubsection{Carbohydrate metabolism and TCA cycle}

Our dataset showed a high abundance of proteins linking glycolysis with the TCA cycle for the aerobic production of ATP such as Pyruvate dehydrogenase (PDH) E1 subunit (alpha type III) in RES clams, as well as Glycogen debranching enzyme (AGL) and Phosphoglucomutase-1 (PGM1) in DIS clams, which may reflect the degradation of carbohydrates for the production of pyruvate, namely in the DIS clam group [82]. This group is also characterized by a greater number of proteins associated with various aspects of the immune response, a process known to be energetically demanding [83]. More importantly, weight loss, decreased glycogen reserves, and condition index, which are indicative of energy imbalance and poor health, have previously been attributed to the negative impact of BRD on energy balance in the Manila clam $[8,84,85]$. Malate dehydrogenase (MDH1), which participates in the TCA cycle by oxidizing malate to form oxaloacetate, was also more abundant in DIS clams, supporting the hypothesis of increased carbohydrate degradation for energy production. Our dataset also indicated a significantly higher abundance of the mitochondrial Phosphoenolpyruvate carboxykinase (PEPCK-M) in the DIS group, which is generally associated with catalyzing the irreversible conversion of oxaloacetate to phosphoenolpyruvate (PEP) for gluconeogenesis. While this appears to contradict the hypothesis of glycogen and glucose degradation, recent studies have demonstrated that overexpression of PEPCK-M (as opposed to the cytosolic form PEPCK-C) may play a role in antiviral immunity in insects, and the accumulation of PEP in infected ticks was suggested to be an antibacterial mechanism against the bacterial pathogen Anaplasma phagocytophilum $[86,87]$.

\subsubsection{Electron transport chain}

The end products of the TCA cycle ultimately convey their electrons to the electron transport chain (ETC), composed of molecules within the inner membrane of the mitochondria, including the essential proteins ubiquinone (coenzyme Q10) and ATP synthase. In the DIS group, the high abundance of 3-demethylubiquinone-9 3-O-methyltransferase, which participates in the final step of ubiquinone synthesis, suggests that there is a high demand for electron acceptor molecules which increase the proton gradient in the inter membrane space of the mitochondria [88]. 


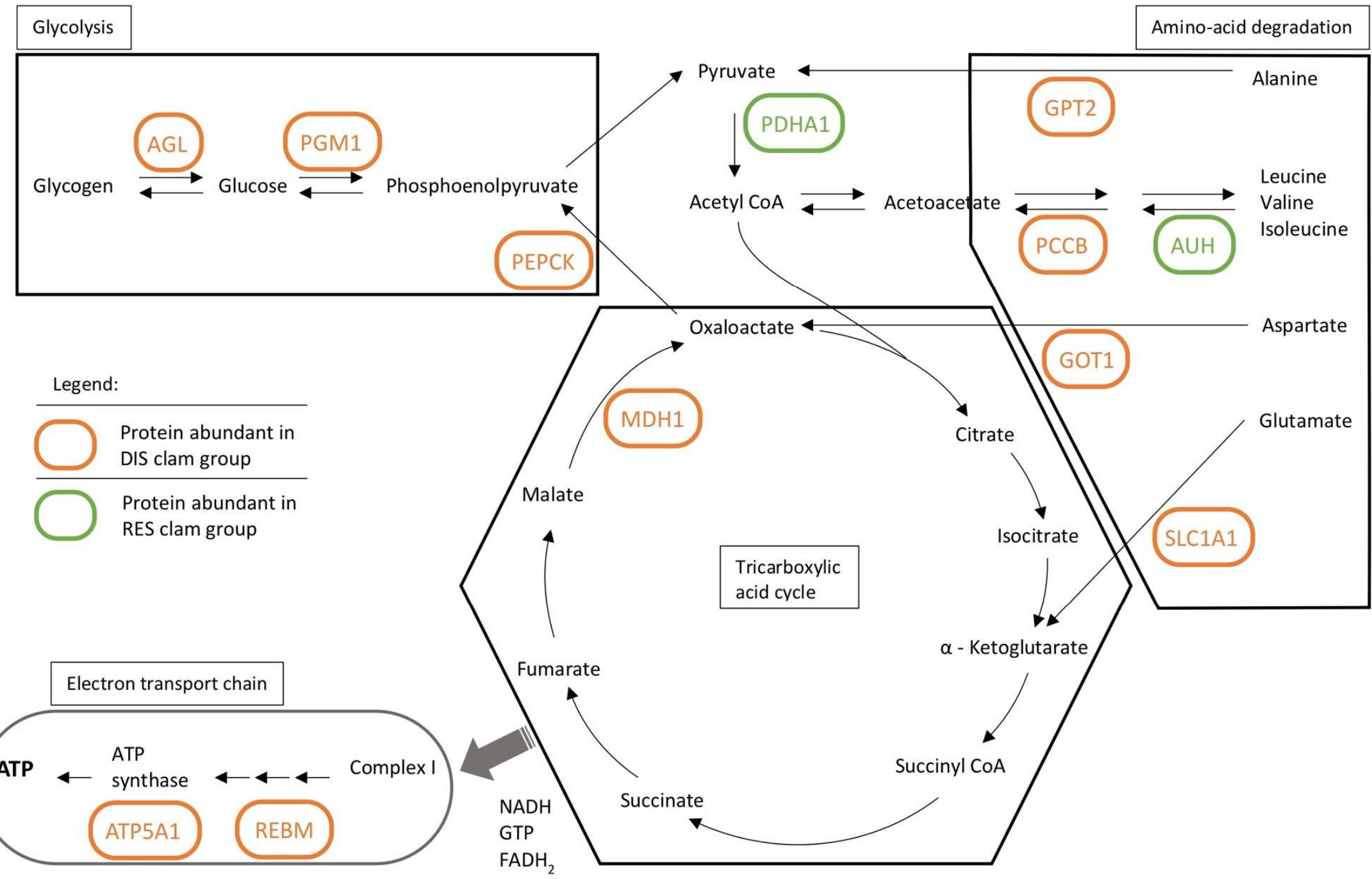

Figure 3: Schematic representation of energy production and the carbohydrate and amino acid metabolisms, including glycolysis, the TCA cycle, amino-acid degradation pathways, and the electron transport chain. The processes in which highly abundant proteins in DIS (orange) and RES (green) clams are implicated are annotated with the abbreviated protein name.

Glycogen debranching enzyme (AGL), Phosphoglucomutase-1 (PGM1), and Phosphoenolpyruvate carboxykinase (PEPCK) are associated to the carbohydrate metabolism (both

glycolysis and gluconeogenesis). Alanine aminotransferase (GPT2), Propionyl-CoA carboxylase beta chain (PCCB), Methylglutaconyl-CoA hydratase (AUH), Aspartate aminotransferase (GOT1), and Excitatory amino-acid transporter-1 (SLC1A1) all participate in the degradation of amino acids that can play a role in replenishing metabolites of the TCA cycle. Malate dehydrogenase 1 (MDH1) is an essential enzyme of the TCA cycle, the high-energy products of which are then shuttles to the electron transport chain where proteins such as 3-demethylubiquinone-9 3-methyltransferase (REBM) and ATP synthase subunit alpha (ATP5A1) participate in the production of ATP. 
429 Overall, proteins associated with the energy metabolism, including ATP synthase subunits and ETC430 associated proteins, as well as proteins associated with energy production from both amino acids and 431 sugars, are more abundant in the DIS group than in the RES group, reflecting a high energy demand likely as a result of the active immune response described previously.

\subsection{PROTEIN METABOLISM}

Seven highly abundant proteins in the dataset were associated with various aspects of protein metabolism, namely proteolysis, transport, and chaperones.

\subsubsection{Proteolysis}

438 Proteolytic processes are represented in our dataset by the proteins cullin-associated NEDD8439 dissociated protein 1 (CAND1) and subunit 4 of the 26S proteasome complex (PSMC1) in the RES 440 group, and by the 26S proteasome non-ATPase regulatory subunit 7 (PSMD7) in the DIS group (Table 441 2). In eukaryotic cells, proteolysis, or the degradation of proteins and recycling of their components, is 442 a process mediated by the conjugation of polyubiquitin chains to proteins which are then recognized by 443 the $26 \mathrm{~S}$ proteasome complex, a multi-subunit enzyme responsible for proteolysis [89]. CAND1 binds 444 to unneddylated CUL1, one of the three major components of an E3 ubiquitin ligase playing an 445 essential role in protein degradation by regulating ligase ubiquitination [90]. Interestingly, ubiquitin 446 ligase complexes were found to be one of the targets of pathogenic bacteria during infection, whereby 447 inhibiting factors produced by pathogens may be able to effectively bind to CUL1, preventing it from 448 correctly forming the ligase complex [91]. PSMC1 coordinates substrate recruitment and translocation 449 into the proteolytic chamber of the proteasome, and is essential for rapid proteolysis [92]. Similarly, 450 PSMD7 is another component of the proteasome important in mediating the recognition of 451 polyubiquitin chains and cleavage of ubiquitin from degraded proteins [93]. In a previous gene452 expression study of $P$. olseni-infected Manila clams, proteasome subunits were found to be 453 downregulated in diseased animals, indicating decreased proteolytic activity [41]. In that respect, the 454 elevated abundance of CAND1 and PSMC1 in RES clams may indicate a trend towards ubiquitin 455 tagging of damaged proteins and more active protein degradation in RES clams than in DIS clams.

456 High proteolytic activity ion RES clams may be linked to the digestion of phagocytosed and 457 neutralized bacteria, and may also reflect the presence of a pro-apoptotic protein in this group. In 458 addition, it may be possible that RES clams were able to sustain the cellular functions necessary for 459 effective elimination of the pathogen, after which proteins damaged by oxidative stress during the 460 immune response are degraded. 
462 Our dataset also contained proteins associated with various aspects of protein synthesis, including 463 protein transport (Table 2). Titin (TTN), a large structural protein thought to function as a scaffold 464 protein, has been shown to interact with actin and filamin, proteins of the cytoskeleton implicated in the movement of cellular components and proteins [94]. In vertebrate striated muscle, TTN was specifically shown to recruit E3 ubiquitin-ligase [95], thus its high abundance in RES clams may reflect transport associated with proteolysis, consistent with the fact that this group also showed higher abundance of CAND1 and a proteasome subunit. Another protein implicated in protein transport is 143-3 epsilon (YWHAE), a binding protein suggested to play a role in protein transport to the secretory pathway, namely through interaction with GTPase-activating proteins such as IQGAP1 (see 3.3.3 Cytoskeleton-associated immune response), also found highly abundant in RES clams [96]. DIS clams showed a high abundance of FK506 binding protein 14 (FKBP14), which is thought to accelerate protein folding as it belongs to a family of peptidyl-prolyl cis-trans isomerases that play a role in the folding of newly synthesized proteins [97]. The higher abundance of this protein in the DIS group may reflect an increase in the synthesis of immune-related proteins, which were also more abundant in DIS clams. Furthermore, it is also interesting to note that this family of proteins (also called immunophilins) has been shown to inhibit early establishment and intracellular infection by bacteria [98]. Though not directly implicated in protein metabolism, the DIS group also presented high abundance of an Abhydrolase domain-containing protein associated with biosynthesis of phosphatidylcholine, an essential class of membrane phospholipids, possibly reflecting an increase in membrane synthesis due to the internalization of bacteria in phagosomes [99].

Heat-shock protein 90 (HSP90), a chaperone protein that plays a crucial role in protecting protein structure in response to stress conditions, was highly abundant in RES clams. Due to its interaction with the major histocompatibility complex (MHC) and the antigen processing pathways in vertebrates [100], HSP90 has been suggested to play a role in the innate immune system response and resistance to infection in invertebrates [101]. As HSP synthesis is promoted by protein denaturation, the trend towards proteolytic activity in RES clams discussed in part 3.5.1 may be partially responsible for activating HSP synthesis. That said, the higher abundance of HSP90 in RES clams may also indicate that resistant clams have a lower threshold for protein denaturation and thus perhaps more rapidly activate the synthesis of protective chaperone proteins, granting them an advantage over DIS clams 
494 The transcriptional activator protein Pur-alpha (PURA), a protein involved in controlling DNA 495 replication and gene transcription processes [102,103], was highly abundant in the DIS group, while a 496 Poly (rc)-binding protein 3 (PCBP3) associated with negative regulation of transcription [104] was 497 highly abundant in the RES group [104].

498 Proteins associated with translation include RPL27A, a structural component of the 60S ribosome 499 subunit whose upregulation has previously been reported in white-spot infected shrimp and in hypoxia500 stressed oysters [105,106], and asparaginyl-tRNA synthetase (NARS), whose primary function in 501 translation is to catalyze the attachment of asparagine to its corresponding tRNA.

502 Finally, four significantly abundant proteins were uncharacterized; three were highly abundant in the 503 DIS group and one in the RES group.

\section{CONCLUSION}

506 Despite being one of the fastest-growing sectors of aquaculture worldwide, mollusk production 507 continues to suffer significant losses due in part to the impact of infectious diseases. The study of 508 proteomic profiles offers the possibility of better understanding the complex functional mechanisms at 509 play during host response to disease, and may shed light on factors associated with resistance to 510 disease.

511 The aim of the present study was to investigate the proteomic profiles of resistance to controlled 512 infection with Vibrio tapetis, the etiological agent of Brown Ring Disease, in the Manila clam, 513 Ruditapes philippinarum. The comparison of proteomic profiles of two extreme phenotypes (RES and 514 DIS) observed in juvenile Manila clams shows a number of functional differences in highly abundant 515 proteins implicated in the immune response-associated processes, energy production, and protein 516 metabolism. Twice as many significantly abundant proteins associated with the immune response were 517 accumulated in the DIS group compared to the RES group, reflecting the ongoing infection as 518 established by the presence of both visual and molecular signs of disease. That said, the function of 519 immune-associated proteins in the RES group was almost consistently associated with redox 520 homeostasis, whereas in DIS group the abundant proteins were mostly involved in pathogen 521 recognition, signaling, and neutralization. This may suggest that disease resistant clams are better 522 equipped to manage ROS production and scavenging in order to simultaneously eliminate the pathogen 523 and protect host cellular components from oxidative stress. Protein degradation as well as protection by 524 chaperones were another process highly represented in resistant clams, with degradation possibly as a 
525 result of successful elimination of the pathogen which may nonetheless have left a number of cellular

526 components damaged by oxidative stress. The fact that only resistant clams showed significantly high

527 abundance of a chaperone-associated protein suggests that this may be an important factor of resistance

528 to disease. In contrast, diseased clams showed a higher abundance of proteins involved in protein 529 synthesis and functional modifications, possibly in response to activation by the immune system in 530 order to continue fighting infection. Both immune response and protein synthesis are energy 531 demanding processes, which is further supported by the presence of proteins involved in glycolysis, 532 TCA cycle, and the electron transport chain. Overall, the comparison of the proteomic profiles of 533 resistant and sick clams suggests that redox homeostasis and maintenance of protein structure by 534 chaperone proteins may play important and interrelated roles in resistance to infection by Vibrio tapetis 535 in the Manila clam.

536

\section{ACKNOWLEDGMENTS}

538 The authors would like to acknowledge the "investment for the future" programs LabexMER (ANR539 10-LABX-19) and ISblue (ANR-17-EURE-0015) for funding international joint PhD agreements and 540 proteomic analyses, the EU Horizon2020 project VIVALDI (grant agreement $\mathrm{N}^{\circ} 678589$ ) for providing 541 funding and biological material. The authors also would like to thank Fabrizio Ghiselli and Mariangela 542 Ianello from the University of Bologna, and Massimo Milan and Luca Bargelloni from the University 543 of Padova, for providing the full annotated and assembled transcriptome of the Manila clam digestive 544 gland used for protein identification. 


\section{REFERENCES}

[1] FAO, The State of World Fisheries and Aquaculture 2018: Meeting the sustainable development goals, 2018. doi:doi:10.18356/8d6ea4b6-en.

[2] J.. Flassch, Y. Leborgne, Introduction in Europe, from 1972 to 1980, of the Japanese Manila clam, ICES Mar. Sci. Symp. 194 (1992) 92-96.

[3] C. Zannella, F. Mosca, F. Mariani, G. Franci, V. Folliero, M. Galdiero, P.G. Tiscar, M. Galdiero, Microbial diseases of bivalve mollusks: Infections, immunology and antimicrobial defense, Mar. Drugs. 15 (2017). doi:10.3390/md15060182.

[4] C. Paillard, P. Maes, R. Oubella, Brown ring disease in clams, Annu. Rev. Fish Dis. 4 (1994) 219-240. doi:10.1016/0959-8030(94)90030-2.

[5] C. Paillard, P. Maes, Etiologie de la maladie de l'anneau brun chez Tapes philippinarum: pathogénicité d'un Vibrio sp., Comptes Rendus l'Académie Des Sci. Série 3, Sci. La Vie. 310 (1990) 15-20.

[6] B. Allam, C. Paillard, M. Auffret, Alterations in hemolymph and extrapallial fluid parameters in the Manila Clam, Ruditapes philippinarum, challenged with the pathogen Vibrio tapetis, J. Invertebr. Pathol. 76 (2000) 63-69. doi:10.1006/jipa.2000.4940.

[7] C. Paillard, F. Le Roux, J.J. Borrego, Bacterial disease in marine bivalves, a review of recent studies: Trends and evolution, Aquat. Living Resour. 17 (2004) 477-498. doi:10.1051/alr:2004054.

[8] C. Paillard, F. Jean, S.E. Ford, E.N. Powell, J.M. Klinck, E.E. Hofmann, J. Flye-Sainte-Marie, A theoretical individual-based model of Brown Ring Disease in Manila clams, Venerupis philippinarum, J. Sea Res. 91 (2014) 15-34. doi:10.1016/j.seares.2014.03.005.

[9] C. Paillard, B. Allam, R. Oubella, Effect of temperature on defense parameters in Manila clam Ruditapes philippinarum challenged with Vibrio tapetis., Dis. Aquat. Organ. 59 (2004) 249-262. doi:10.3354/dao059249.

[10] H.I. Reid, P. Soudant, C. Lambert, C. Paillard, T.H. Birkbeck, Salinity effects on immune parameters of Ruditapes philippinarum challenged with Vibrio tapetis, Dis. Aquat. Organ. 56 (2003) 249-258. doi:10.3354/dao056249.

[11] B. Allam, E. Pales Espinosa, Bivalve immunity and response to infections: Are we looking at the right place?, Fish Shellfish Immunol. 53 (2016) 4-12. doi:10.1016/j.fsi.2016.03.037.

[12] B. Allam, C. Paillard, Defense factors in clam extrapallial fluids, Dis. Aquat. Organ. 33 (1998) 123-128. doi:10.3354/dao033123.

[13] N. Trinkler, G. Sinquin, J. Querne, C. Paillard, Resistance to Brown Ring Disease in the Manila clam, Ruditapes philippinarum: A study of selected stocks showing a recovery process by shell repair, J. Invertebr. Pathol. 104 (2010) 8-16. doi:10.1016/j.jip.2009.12.007.

[14] F. Jeffroy, F. Brulle, C. Paillard, Differential expression of genes involved in immunity and 
biomineralization during Brown Ring Disease development and shell repair in the Manila clam, Ruditapes philippinarum, J. Invertebr. Pathol. 113 (2013) 129-136. doi:10.1016/J.JIP.2013.03.001.

[15] M. Milan, A. Coppe, R. Reinhardt, L.M. Cancela, R.B. Leite, C. Saavedra, C. Ciofi, G. Chelazzi, T. Patarnello, S. Bortoluzzi, L. Bargelloni, Transcriptome sequencing and microarray development for the Manila clam, Ruditapes philippinarum: genomic tools for environmental monitoring, BMC Genomics. 12 (2011) 234. doi:10.1186/1471-2164-12-234.

[16] Y. Lee, W.D.N. Wickamarachchi, I. Whang, M. Oh, N. Umasuthan, M. De Zoysa, C. Oh, D.H. Kang, J. Lee, Immune response-related gene expression profile of a novel molluscan IкB protein member from Manila clam (Ruditapes philippinarum), Mol. Biol. Rep. 40 (2013) 1519-1527. doi:10.1007/s11033-0122196-5.

[20] G. Richard, C. Le Bris, F. Guérard, C. Lambert, C. Paillard, Immune responses of phenoloxidase and

[21] G. Richard, F. Guérard, C. Corporeau, C. Lambert, C. Paillard, F. Pernet, Metabolic responses of clam superoxide dismutase in the manila clam Venerupis philippinarum challenged with Vibrio tapetis - Part doi:10.1016/j.fsi.2014.12.039. de Zoysa, Manila clam, Ruditapes philippinarum Cathepsin D : Molecular analysis and immune response against brown ring disease causing Vibrio tapetis challenge, Korean J. Malacol. 29 (2013) 155-161. doi:10.9710/kjm.2013.29.2.155.

[18] B. Allam, E. Pales Espinosa, A. Tanguy, F. Jeffroy, C. Le Bris, C. Paillard, Transcriptional changes in Manila clam (Ruditapes philippinarum) in response to Brown Ring Disease, Fish Shellfish Immunol. 41 (2014) 2-11. doi:10.1016/j.fsi.2014.05.022.

[19] F. Brulle, F. Jeffroy, S. Madec, J.L. Nicolas, C. Paillard, Transcriptomic analysis of Ruditapes philippinarum hemocytes reveals cytoskeleton disruption after in vitro Vibrio tapetis challenge, Dev. Comp. Immunol. 38 (2012) 368-376. doi:10.1016/j.dci.2012.03.003. Ruditapes philippinarum exposed to its pathogen Vibrio tapetis in relation to diet, Dev. Comp. Immunol. 60 (2016) 96-107. doi:10.1016/j.dci.2016.02.026.

22] B. Marie, N. Trinkler, I. Zanella-Cleon, N. Guichard, M. Becchi, C. Paillard, F. Marin, Proteomic Identification of Novel Proteins from the Calcifying Shell Matrix of the Manila Clam Venerupis Philippinarum, Mar. Biotechnol. 13 (2011) 955-962. doi:10.1007/s10126-010-9357-0.

[23] C. Paillard, An Ecological Approach To Understanding Host-Pathogen-Environment Interactions: the Case of Brown Ring Disease in Clams, in: Oysters Clams Cultiv. Habitat Threat. Ecol. Impact, Nova Science Publishers, Inc. (NOVA), 2016.

R. Moreira, P. Balseiro, A. Romero, S. Dios, D. Posada, B. Novoa, A. Figueras, Gene expression analysis of clams Ruditapes philippinarum and Ruditapes decussatus following bacterial infection yields 
molecular insights into pathogen resistance and immunity, Dev. Comp. Immunol. 36 (2012) 140-149. doi:10.1016/j.dci.2011.06.012.

[25] R. Moreira, M. Milan, P. Balseiro, A. Romero, M. Babbucci, A. Figueras, L. Bargelloni, B. Novoa, Gene expression profile analysis of Manila clam (Ruditapes philippinarum) hemocytes after a Vibrio alginolyticus challenge using an immune-enriched oligo-microarray, BMC Genomics. 15 (2014) 267. doi:10.1186/1471-2164-15-267.

[26] H. Nie, X. Yan, Z. Huo, L. Jiang, P. Chen, H. Liu, J. Ding, F. Yang, Construction of a high-density genetic map and quantitative trait locus mapping in the Manila clam Ruditapes philippinarum, Sci. Rep. 7 (2017) 1-9. doi:10.1038/s41598-017-00246-0.

[27] F. Ghiselli, A. Komissarov, L. Milani, J. Dunham, S. Breton, S. Nuzhdin, M. Passamonti, The draft genome of Ruditapes philippinarum (the Manila clam), a promising model system for mitochondrial biology, 2017. doi:10.7287/peerj.preprints.3096.

[28] A. Bidault, G. Richard, C. Le Bris, C. Paillard, Development of a Taqman real-time PCR assay for rapid detection and quantification of Vibrio tapetis in extrapallial fluids of clams, PeerJ. 3 (2015) e1484. doi:10.7717/peerj.1484.

[29] C. Paillard, P. Maes, Brown ring disease in the Manila clam Ruditapes philippinarum: Establishment of a classification system, Dis. Aquat. Organ. 19 (1994) 137-146. doi:10.3354/dao019137.

[30] M.M. Bradford, A rapid and sensitive method for the quantitation of microgram quantities of protein utilizing the principle of protein-dye binding, Anal. Biochem. 72 (1976) 248-254. doi:10.1016/00032697(76)90527-3.

[31] S. Tyanova, T. Temu, P. Sinitcyn, A. Carlson, M.Y. Hein, T. Geiger, M. Mann, J. Cox, The Perseus computational platform for comprehensive analysis of (prote)omics data, Nat. Methods. 13 (2016) 731740. doi:10.1038/nmeth.3901.

[32] B. Allam, S.E. Ford, Effects of the pathogenic Vibrio tapetis on defence factors of susceptible and nonsusceptible bivalve species: I. Haemocyte changes following in vitro challenge, Fish Shellfish Immunol. 20 (2006) 374-383. doi:10.1016/j.fsi.2005.05.012.

[33] G.R. Vasta, C. Feng, M.A. Bianchet, T.R. Bachvaroff, S. Tasumi, Structural, functional, and evolutionary aspects of galectins in aquatic mollusks: From a sweet tooth to the Trojan horse, Fish Shellfish Immunol. 46 (2015) 94-106. doi:10.1016/j.fsi.2015.05.012.

[34] A. Chaosomboon, B. Phupet, O. Rattanaporn, P. Runsaeng, P. Utarabhand, Lipopolysaccharide- and $\beta$ 1,3-glucan-binding protein from Fenneropenaeus merguiensis functions as a pattern recognition receptor with a broad specificity for diverse pathogens in the defense against microorganisms, Dev. Comp. Immunol. 67 (2017) 434-444. doi:10.1016/j.dci.2016.07.006.

[35] S.S. Jayaraj, R. Thiagarajan, M. Arumugam, P. Mullainadhan, Isolation, purification and characterization of $\beta$-1,3-glucan binding protein from the plasma of marine mussel Perna viridis, Fish Shellfish Immunol. 
24 (2008) 715-725. doi:10.1016/j.fsi.2007.11.012.

[36] D. Ricklin, E.S. Reis, D.C. Mastellos, P. Gros, J.D. Lambris, Complement component C3 - The "Swiss Army Knife" of innate immunity and host defense, Immunol. Rev. 274 (2016) 33-58. doi:10.1111/imr.12500.

[37] D.A. Raftos, R. Kuchel, S. Aladaileh, D. Butt, Infectious microbial diseases and host defense responses in sydney rock oysters, Front. Microbiol. 5 (2014) 135. doi:10.3389/fmicb.2014.00135.

[38] B. Bezemer, D. Butt, J. Nell, R. Adlard, D. Raftos, Breeding for QX disease resistance negatively selects one form of the defensive enzyme, phenoloxidase, in Sydney rock oysters, Fish Shellfish Immunol. 20 (2006) 627-636. doi:10.1016/j.fsi.2005.08.007.

[39] H. Zhang, L. Song, C. Li, J. Zhao, H. Wang, L. Qiu, D. Ni, Y. Zhang, A novel C1q-domain-containing protein from Zhikong scallop Chlamys farreri with lipopolysaccharide binding activity, Fish Shellfish Immunol. 25 (2008) 281-289. doi:10.1016/j.fsi.2008.06.003.

[40] M. Gerdol, C. Manfrin, G. De Moro, A. Figueras, B. Novoa, P. Venier, A. Pallavicini, The C1q domain containing proteins of the Mediterranean mussel Mytilus galloprovincialis: A widespread and diverse family of immune-related molecules, Dev. Comp. Immunol. 35 (2011) 635-643. doi:10.1016/j.dci.2011.01.018.

[41] A. Romero, G. Forn-Cuní, R. Moreira, M. Milan, L. Bargelloni, A. Figueras, B. Novoa, An immuneenriched oligo-microarray analysis of gene expression in Manila clam (Venerupis philippinarum) haemocytes after a Perkinsus olseni challenge, Fish Shellfish Immunol. 43 (2015) 275-286. doi:10.1016/j.fsi.2014.12.029.

[42] J. Arivalagan, T. Yarra, B. Marie, V.A. Sleight, E. Duvernois-Berthet, M.S. Clark, A. Marie, S. Berland, Insights from the Shell Proteome: Biomineralization to Adaptation, Mol. Biol. Evol. 34 (2017) 66-77. doi:10.1093/molbev/msw219.

[43] H. Kim, C.D. White, D.B. Sacks, IQGAP1 in microbial pathogenesis: Targeting the actin cytoskeleton, FEBS Lett. 585 (2011) 723-729. doi:10.1016/j.febslet.2011.01.041.

[44] J. Harris, N. Schwinn, J.A. Mahoney, H.-H.H. Lin, M. Shaw, C.J. Howard, R.P. da Silva, S. Gordon, A vitellogenic-like carboxypeptidase expressed by human macrophages is localized in endoplasmic reticulum and membrane ruffles, Int. J. Exp. Pathol. 87 (2006) 29-39. doi:10.1111/j.09599673.2006.00450.x.

[45] K. Gao, S. Zhang, Ovochymase in amphioxus Branchiostoma belcheri is an ovary-specific trypsin-like serine protease with an antibacterial activity, Dev. Comp. Immunol. 33 (2009) 1219-1228. doi:10.1016/j.dci.2009.07.002.

[46] Y. Wei, Z.J. Xiong, J. Li, C. Zou, C.W. Cairo, J.S. Klassen, G.G. Privé, Crystal structures of human lysosomal EPDR1 reveal homology with the superfamily of bacterial lipoprotein transporters, Commun. Biol. 2 (2019) 1-13. doi:10.1038/s42003-018-0262-9. 
B.A. Bannan, J. Van Etten, J.A. Kohler, Y. Tsoi, N.M. Hansen, S. Sigmon, E. Fowler, H. Buff, T.S. Williams, J.G. Ault, R.L. Glaser, C.A. Korey, The drosophila protein palmitoylome characterizing palmitoyl-thioesterases and DHHC palmitoyl-transferases, Fly (Austin). 2 (2008) 198-214. doi:10.4161/fly.6621.

[48] S. Balomenou, S. Arnaouteli, D. Koutsioulis, V.E. Fadouloglou, V. Bouriotis, Polysaccharide Deacetylases: New Antibacterial Drug Targets, in: Front. Anti-Infective Drug Discov., 2015: pp. 68-130. doi:10.2174/9781681080826115040005.

[49] G. Pei, M. Bronietzki, M.G. Gutierrez, Immune regulation of Rab proteins expression and intracellular transport, J. Leukoc. Biol. 92 (2012) 41-50. doi:10.1189/jlb.0212076.

[50] R. Linhart, S.A. Wong, J. Cao, M. Tran, A. Huynh, C. Ardrey, J.M. Park, C. Hsu, S. Taha, R. Peterson, S. Shea, J. Kurian, K. Venderova, Vacuolar protein sorting 35 (Vps35) rescues locomotor deficits and shortened lifespan in Drosophila expressing a Parkinson's disease mutant of Leucine-rich repeat kinase 2 (LRRK2), Mol. Neurodegener. 9 (2014) 1-10. doi:10.1186/1750-1326-9-23.

[51] S. Fernández-Boo, A. Villalba, A. Cao, Protein expression profiling in haemocytes and plasma of the Manila clam Ruditapes philippinarum in response to infection with Perkinsus olseni, J. Fish Dis. 39 (2016) 1369-1385. doi:10.1111/jfd.12470.

[52] A. Rahmani, E. Corre, G. Richard, A. Bidault, L. Oliveira, F. Thompson, C. Paillard, V. Pichereau, Transcriptomic analysis of clam extra pallial fluids reveals immunity and cytoskeleton alterations in the first week of brown ring disease development, Fish Shellfish Immunol. 91 (2019) 466. doi:10.1016/j.fsi.2019.04.275.

[53] R.M. Ortiz Flores, J.S. Distel, M.O. Aguilera, W. Berón, The role of microtubules and the dynein/ dynactin motor complex of host cells in the biogenesis of the Coxiella burnetii-containing vacuole, 2019. doi:10.1371/journal.pone.0209820.

[54] S.R. Gill, T.A. Schroer, I. Szilak, E.R. Steuer, M.P. Sheetz, D.W. Cleveland, Dynactin, a conserved, ubiquitously expressed component of an activator of vesicle motility mediated by cytoplasmic dynein, J. Cell Biol. 115 (1991) 1639-1650. doi:10.1083/jcb.115.6.1639.

[55] R.S. Flannagan, G. Cosío, S. Grinstein, Antimicrobial mechanisms of phagocytes and bacterial evasion strategies, Nat. Rev. Microbiol. 7 (2009) 355-366. doi:10.1038/nrmicro2128.

[56] A. Romero, B. Novoa, A. Figueras, The complexity of apoptotic cell death in mollusks: An update, Fish Shellfish Immunol. 46 (2015) 79-87. doi:10.1016/j.fsi.2015.03.038.

[57] B. Morga, T. Renault, N. Faury, I. Arzul, New insights in flat oyster Ostrea edulis resistance against the parasite Bonamia ostreae, Fish Shellfish Immunol. 32 (2012) 958-968. doi:10.1016/j.fsi.2012.01.026.

[58] J. Pawlowski, A.S. Kraft, Bax-induced apoptotic cell death, Proc. Natl. Acad. Sci. 97 (2002) 529-531. doi:10.1073/pnas.97.2.529.

[59] Y. Takahashi, M. Karbowski, H. Yamaguchi, A. Kazi, J. Wu, S.M. Sebti, R.J. Youle, H.-G. Wang, Loss 
of Bif-1 Suppresses Bax/Bak Conformational Change and Mitochondrial Apoptosis, Mol. Cell. Biol. 25 (2005) 9369-9382. doi:10.1128/mcb.25.21.9369-9382.2005.

[60] H. Mutsuzaki, H. Nakajima, Y. Wadano, S. Furuhata, M. Sakane, Influence of knee immobilization on chondrocyte apoptosis and histological features of the anterior cruciate ligament insertion and articular cartilage in rabbits, Int. J. Mol. Sci. 18 (2017). doi:10.3390/ijms18020253.

[61] G.H. Semerjyan, H.H. Semerjyan, A.H. Trchounian, Effects of $\mathrm{Mg} 2+, \mathrm{Cd} 2+, \mathrm{Cu} 2+\mathrm{Low}$ Concentrations and Immobilization Stress on the Activity of Adenosine Deaminase in Different Organs of Rabbits, Proc. Yerevan State Univ. Chem. Biol. 52 (2018) 122-127.

[62] L. Chen, Q. He, Y. Liu, Y. Wu, D. Ni, J. Liu, Y. Hu, Y. Gu, Y. Xie, Q. Zhou, Q. Li, PPP3CB Inhibits Migration of G401 Cells via Regulating Epithelial-to-Mesenchymal Transition and Promotes G401 Cells Growth, Int. J. Mol. Sci. 20 (2019) 275. doi:10.3390/ijms20020275.

[63] R.S. Anderson, Reactive oxygen species and antimicrobial defenses of invertebrates: A bivalve model, in: Adv. Exp. Med. Biol., 2001: pp. 131-139. doi:10.1007/978-1-4615-1291-2_12.

[65] H.A. Chawsheen, Q. Ying, H. Jiang, Q. Wei, A critical role of the thioredoxin domain containing protein

[66] E. Horna-Terrón, A. Pradilla-Dieste, C. Sánchez-de-Diego, J. Osada, TXNDC5, a newly discovered

[67] N. Umasuthan, K. Saranya Revathy, Y. Lee, I. Whang, J. Lee, Mitochondrial thioredoxin-2 from Manila

[68] Z. Liu, H. Zhu, Y. Liu, J. Kuang, K. Zhou, F. Liang, Z. Liu, D. Wang, W. Ke, Construction of a high-

[69] C. Vorbach, R. Harrison, M.R. Capecchi, Xanthine oxidoreductase is central to the evolution and 
oxidative response and bactericidal activity of neutrophils, Blood. 130 (2017) 328-339. doi:10.1182/blood-2016-11-752006.

[72] S. Di Meo, T.T. Reed, P. Venditti, V.M. Victor, Role of ROS and RNS Sources in Physiological and Pathological Conditions, Oxid. Med. Cell. Longev. 2016 (2016) 1-44. doi:10.1155/2016/1245049.

[73] Y. Zhou, J. Tan, Y. Dai, Y. Yu, Q. Zhang, M.E. Meyerhoff, Synthesis and nitric oxide releasing

[75] C. Tafalla, B. Novoa, A. Figueras, Production of nitric oxide by mussel (Mytilus galloprovincialis)

[76] P.C. Calder, Branched-Chain Amino Acids and Immunity, J. Nutr. 136 (2006) 288S-293S.

[78] T. V. Nguyen, A.C. Alfaro, T. Young, S. Ravi, F. Merien, Metabolomics Study of Immune Responses of

[79] R.L. Taber, A. Campbell, S. Spencer, A simple experiment demonstrating the allosteric regulation of

[80] A. Van Waarde, Biochemistry of non-protein nitrogenous compounds in fish including the use of amino

[81] Y. Kanai, M.A. Hediger, The glutamate/neutral amino acid transporter family SLC1: Molecular,

[82] M.S. Patel, N.S. Nemeria, W. Furey, F. Jordan, The pyruvate dehydrogenase complexes: Structure-based

[83] K. Brokordt, Y. Defranchi, I. Espósito, C. Cárcamo, P. Schmitt, L. Mercado, E. De la Fuente-Ortega,

[84] J. Flye-Sainte-Marie, An ecophysiological approach of Brown Ring Disease in the Manila clam, 
[85] P. Goulletquer, A bibliography of the Manila Clam Tapes philippinarum, IFREMER La Tremblade, France, 1997.

[86] H. Guo, G. Xu, B. Wang, F. Xia, Q. Sun, Y. Wang, E. Xie, Z. Lu, L. Jiang, Q. Xia, Phosphoenolpyruvate carboxykinase is involved in antiviral immunity against Bombyx mori nucleopolyhedrovirus, Dev. Comp. Immunol. 92 (2019) 193-198. doi:10.1016/j.dci.2018.11.015.

[87] A. Cabezas-Cruz, P.J. Espinosa, D.A. Obregón, P. Alberdi, J. de la Fuente, Ixodes scapularis Tick Cells Control Anaplasma phagocytophilum Infection by Increasing the Synthesis of Phosphoenolpyruvate from Tyrosine, Front. Cell. Infect. Microbiol. 7 (2017) 1-16. doi:10.3389/fcimb.2017.00375.

[88] E.P. Sokolov, S. Markert, T. Hinzke, C. Hirschfeld, D. Becher, S. Ponsuksili, I.M. Sokolova, Effects of

[89] C.M. Pickart, R.E. Cohen, Proteasomes and their kin: Proteases in the machine age, Nat. Rev. Mol. Cell Biol. 5 (2004) 177-187. doi:10.1038/nrm1336.

[90] J. Zheng, X. Yang, J.M. Harrell, S. Ryzhikov, E.-H. Shim, K. Lykke-Andersen, N. Wei, H. Sun, R. Kobayashi, H. Zhang, CAND1 Binds to Unneddylated CUL1 and Regulates the Formation of SCF Ubiquitin E3 Ligase Complex, Mol. Cell. 10 (2002) 1519-1526. doi:10.1016/s1097-2765(02)00784-0.

[92] R. Rosenzweig, P.A. Osmulski, M. Gaczynska, M.H. Glickman, The central unit within the 19S

[93] K. Shi, J.Z. Zhang, R.L. Zhao, L. Yang, D. Guo, PSMD7 downregulation induces apoptosis and

[94] N. González-Morales, T.K. Holenka, F. Schöck, Filamin actin-binding and titin-binding fulfill distinct

[95] M. Mrosek, D. Labeit, S. Witt, H. Heerklotz, E. von Castelmur, S. Labeit, O. Mayans, Molecular

[96] T. Mrowiec, B. Schwappach, 14-3-3 Proteins in membrane protein transport, Biol. Chem. 387 (2006) 1227-1236. doi:10.1515/BC.2006.152.

820 [97] P.E. Shaw, Peptidyl-prolyl isomerases: a new twist to transcription., EMBO Rep. 3 (2002) 521-6. doi:10.1093/embo-reports/kvf118.

[98] A. Bella, P. Monaghana, A.P. Page, Peptidyl-prolyl cis-trans isomerases (immunophilins) and their roles in parasite biochemistry, host-parasite interaction and antiparasitic drug action, Int. J. 36 (2009) 261- 
276.

825 [99] G. Van Meer, D.R. Voelker, G.W. Feigenson, Membrane lipids: where they are and how they behave, Nat. Rev. Mol. Cell Biol. 101 (2009) 1-4. doi:10.1038/nrm2330.Membrane.

[100] T. Imai, Y. Kato, C. Kajiwara, S. Mizukami, I. Ishige, T. Ichiyanagi, M. Hikida, J.-Y. Wang, H. Udono, Heat shock protein 90 (HSP90) contributes to cytosolic translocation of extracellular antigen for crosspresentation by dendritic cells, Proc. Natl. Acad. Sci. 108 (2011) 16363-16368. doi:10.1073/pnas.1108372108.

[101] Y. Yik Sung, T.H. MacRae, Heat Shock Proteins and Disease Control in Aquatic Organisms, J. Aquac. Res. Dev. S2 (2011). doi:10.4172/2155-9546.s2-006.

[102] N. Darbinian, G.L. Gallia, M. Kundu, N. Shcherbik, A. Tretiakova, A. Giordano, K. Khalili, Association of Pur $\alpha$ and E2F-1 suppresses transcriptional activity of E2F-1, Oncogene. 18 (1999) 6398-6402. doi:10.1038/sj.onc.1203011.

[103] B. Rocher, F. Bultelle, P. Chan, F. Foll, J. Letendre, T. Monsinjon, S. Olivier, R. Péden, A. Poret, D. Vaudry, T. Knigge, 2-DE Mapping of the Blue Mussel Gill Proteome: The Usual Suspects Revisited, Proteomes. 3 (2015) 3-41. doi:10.3390/proteomes3010003.

[104] D.H. Kang, K.Y. Song, H.S. Choi, P.Y. Law, L.N. Wei, H.H. Loh, Novel dual-binding function of a poly (C)-binding protein 3, transcriptional factor which binds the double-strand and single-stranded DNA sequence, Gene. 501 (2012) 33-38. doi:10.1016/j.gene.2012.04.001.

[105] R. Wongpanya, T. Aoki, I. Hirono, M. Yasuik, A. Tassanakajon, Analysis of gene expression in haemocytes of shrimp Penaeus monodon challenged with white Spot syndrome virus by cDNA microarray, ScienceAsia. 33 (2007) 165-174. doi:10.2306/scienceasia1513-1874.2007.33.165.

[106] E. David, A. Tanguy, K. Pichavant, D. Moraga, Response of the Pacific oyster Crassostrea gigas to hypoxia exposure under experimental conditions, FEBS J. 272 (2005) 5635-5652. doi:10.1111/j.17424658.2005.04960.x. 
Figure 1: Schematic representation of the kinetics of Brown ring disease development during 30 days post injection (DPI) in a controlled challenge, adapted from Bidault et al. 2015, showing concentration of $V$. tapetis in extrapallial fluids (cells. $\mathrm{mL}^{-1}$ ) and limit of detection (LOD) at $1 \times 10^{1}$ cells. "RES" clams are negative for both visual and molecular diagnosis. Bacteria enter the extrapallial compartment and become quantifiable at point (a), then proliferate rapidly (clams at this stage are termed "CAT 1" in our study), with highest concentrations generally observed around 7 DPI. The host then begins to trap the bacteria within the conchiolin deposits characteristic of Brown ring disease, thus leading to a decrease in the concentration of bacteria in the extrapallial compartment (clams at this stage are termed "CAT 2" in our study), represented by point (b). Clams can thus be positive for the visual diagnosis and negative for molecular diagnosis whilst the bacteria remain trapped against the inner surface of the shell, a process during which the host attempts to recalcify over the bacterial biofilm. In the case of "DIS" clams, conchiolin deposits are present but insufficient in limiting the pathogen, which will continue to proliferate (point (c), also termed "CAT 3" for this study) and reach high concentrations in the extrapallial compartment once more. 
Figure 2: Number of proteins per functional group (i.e. "immune response", "energy production", "protein metabolism") that were more abundant in DIS clams (dark bars) and in RES clams (light bars). 
Figure 3: Schematic representation of energy production and the carbohydrate and amino acid metabolisms, including glycolysis, the TCA cycle, amino-acid degradation pathways, and the electron transport chain. The processes in which highly abundant proteins in DIS (orange) and RES (green) clams are implicated are annotated with the abbreviated protein name. Glycogen debranching enzyme (AGL), Phosphoglucomutase-1 (PGM1), and Phosphoenolpyruvate carboxykinase (PEPCK) are associated to the carbohydrate metabolism (both glycolysis and gluconeogenesis). Alanine aminotransferase (GPT2), Propionyl-CoA carboxylase beta chain (PCCB), Methylglutaconyl-CoA hydratase (AUH), Aspartate aminotransferase (GOT1), and Excitatory amino-acid transporter-1 (SLC1A1) all participate in the degradation of amino acids that can play a role in replenishing metabolites of the TCA cycle. Malate dehydrogenase 1 (MDH1) is an essential enzyme of the TCA cycle, the high-energy products of which are then shuttles to the electron transport chain where proteins such as 3-demethylubiquinone-9 3-methyltransferase (REBM) and ATP synthase subunit alpha (ATP5A1) participate in the production of ATP. 
(a)

(b)

(c)

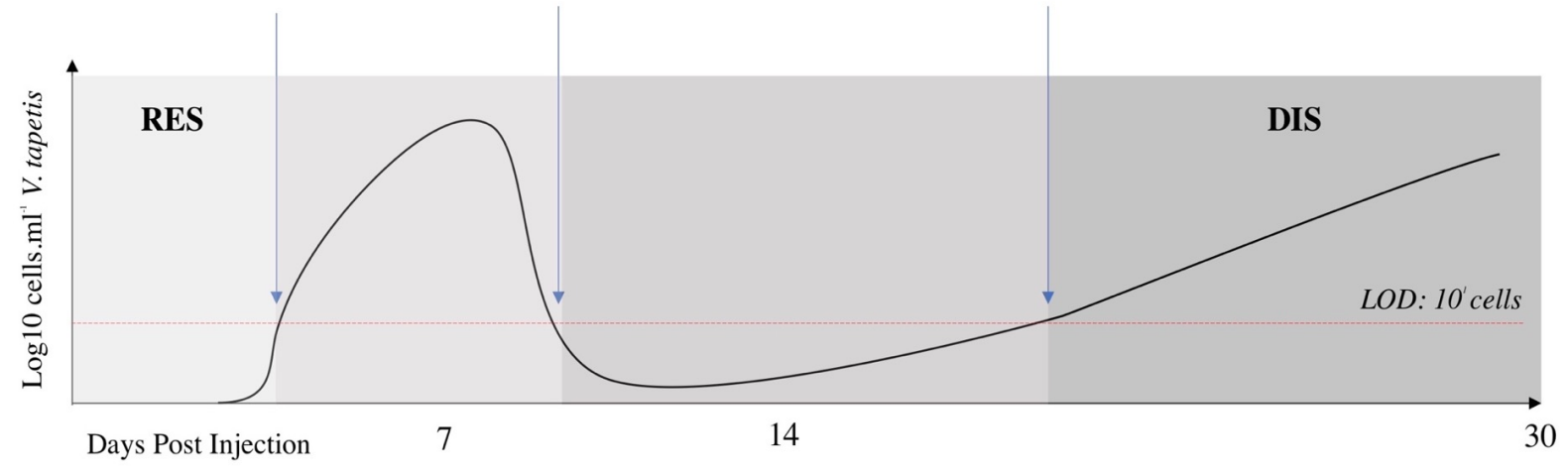

(ad. Bidault et al. 2015) 
Disribution of significantly abundant proteins $(\mathrm{FC}>1.5)$ in resistant ("RES") and diseased ("DIS") clams, by functional groups.

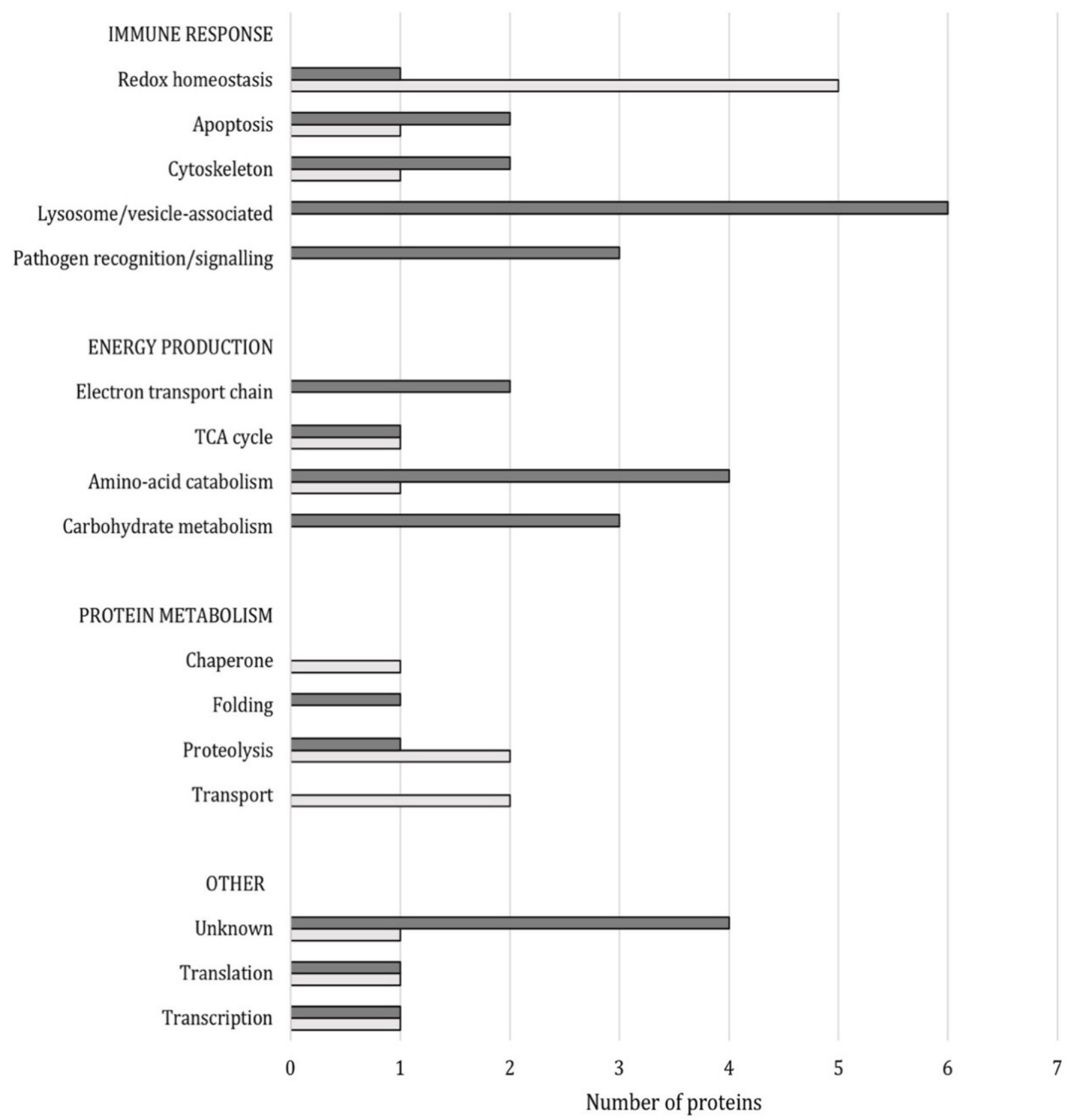

口DIS QRES 


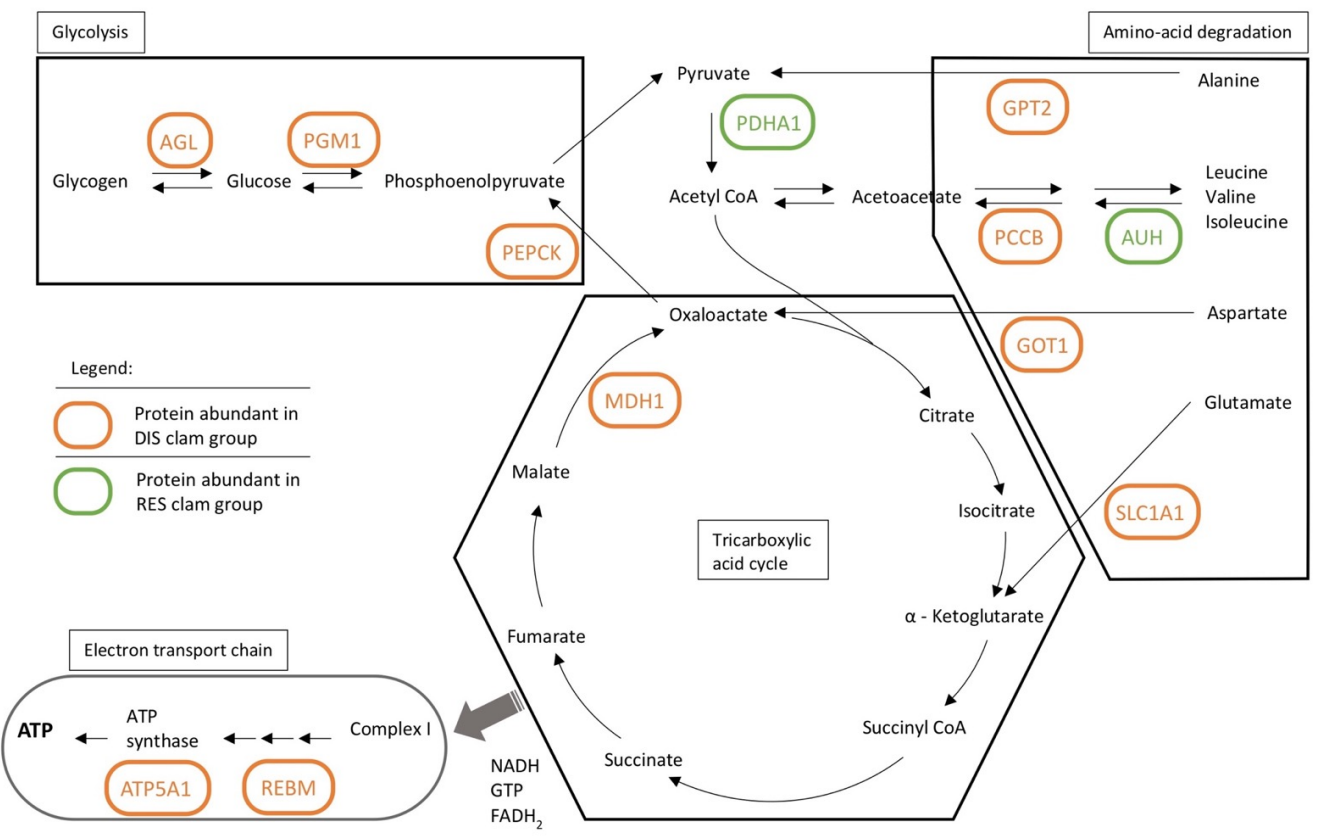




\section{Highlights}

1. Diseased Ruditapes philippinarum show higher abundance of proteins associated with pathogen recognition and neutralization

2. Proteins associated with energy production metabolisms are more abundant in diseased clams

3. Healthy clams post-challenge showed higher abundance of proteins associated with redox homeostasis

4. Long-term resistance of Ruditapes philippinarum to infection with Vibrio tapetis may be linked to ability to balance redox response and maintain protein structure 